\title{
Climatology and trends in the forcing of the stratospheric zonal-mean flow
}

\author{
E. Monier ${ }^{1}$ and B. C. Weare ${ }^{2}$ \\ ${ }^{1}$ Joint Program on the Science and Policy of Global Change, Massachusetts Institute of Technology, Cambridge, \\ Massachusetts, USA \\ ${ }^{2}$ Atmospheric Science Program, Department of Land, Air and Water Resources, University of California, Davis, Davis, \\ California, USA \\ Received: 30 March 2011 - Published in Atmos. Chem. Phys. Discuss.: 14 April 2011 \\ Revised: 15 November 2011 - Accepted: 4 December 2011 - Published: 16 December 2011
}

\begin{abstract}
The momentum budget of the Transformed Eulerian-Mean (TEM) equation is calculated using the European Centre for Medium-Range Weather Forecasts (ECMWF) reanalysis (ERA-40) and the National Centers for Environmental Prediction (NCEP) Reanalysis 2 (R-2). This study outlines the considerable contribution of unresolved waves, deduced to be gravity waves, to the forcing of the zonal-mean flow. A trend analysis, from 1980 to 2001, shows that the onset and break down of the Northern Hemisphere $(\mathrm{NH})$ stratospheric polar night jet has a tendency to occur later in the season in the more recent years. This temporal shift follows long-term changes in planetary wave activity that are mainly due to synoptic waves, with a lag of one month. In the Southern Hemisphere (SH), the polar vortex shows a tendency to persist further into the SH summertime. This also follows a statistically significant decrease in the intensity of the stationary EP flux divergence over the 19802001 period. Ozone depletion is well known for strengthening the polar vortex through the thermal wind balance. However, the results of this work show that the SH polar vortex does not experience any significant long-term changes until the month of December, even though the intensification of the ozone hole occurs mainly between September and November. This study suggests that the decrease in planetary wave activity in November provides an important feedback to the zonal wind as it delays the breakdown of the polar vortex. In addition, the absence of strong eddy feedback before November explains the lack of significant trends in the polar vortex in the SH early spring. A long-term weakening in the Brewer-Dobson (B-D) circulation in the polar region is identified in the $\mathrm{NH}$ winter and early spring and during the
\end{abstract}

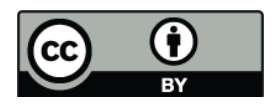

Correspondence to: E. Monier (emonier@mit.edu)
SH late spring and is likely driven by the decrease in planetary wave activity previously mentioned. During the rest of the year, there are large discrepancies in the representation of the B-D circulation and the unresolved waves between the two reanalyses, making trend analyses unreliable.

\section{Introduction}

Understanding stratospheric dynamics, its variability and interaction with photochemical processes has become increasingly important for the climate community. In the last decade, there has been growing evidence that the stratosphere can significantly influence the tropospheric weather and climate (Haynes, 2005; Baldwin et al., 2007). Baldwin and Dunkerton (2001) found that large circulation anomalies in the lower stratosphere precede tropospheric anomalies in the Arctic and North Atlantic Oscillations, and in the location of storm tracks. Therefore, understanding variations in the general circulation of the stratosphere could provide additional tropospheric extended-range forecasting skills (Baldwin and Dunkerton, 2001; Kuroda, 2008). There are many theories describing how the stratosphere can impact the troposphere, such as the downward reflection of wave flux (Perlwitz and Harnik, 2003) or the downward control (Song and Robinson, 2004). Hartley et al. (1998) and Black (2002) have shown that any change in the potential vorticity (PV) in the lower stratosphere induces instantaneous changes in wind and temperature at the tropopause that lead to feedbacks on the troposphere. Also, several studies reveal that the Arctic Oscillation (AO) can propagate downward from the stratosphere to the troposphere (Baldwin and Dunkerton, 1999; Kuroda and Kodera, 1999, 2004; Limpasuvan et al., 2005). Finally, Ineson and Scaife (2009) show that the stratosphere

Published by Copernicus Publications on behalf of the European Geosciences Union. 
plays a significant role in the European climate response to El Niño-Southern Oscillation (ENSO). For these reasons, a comprehensive understanding of the stratospheric dynamics variability and its causes is necessary in order to fully appreciate the potential impact of the stratosphere on climate change. In addition, several studies have shown that the stratospheric dynamics have undergone significant changes in the last few decades. The Southern Hemisphere (SH) stratosphere exhibits a trend towards stronger westerly winds in the summer-fall season, producing a delay in the breakup of the polar vortex (Thompson and Solomon, 2002; Renwick, 2004). Karpetchko et al. (2005) show that wave forcing is not responsible for this long-term change and the trend is mainly attributed to Antarctic ozone depletion. As ozone loss in the polar region leads to an enhanced meridional temperature gradient near the subpolar stratosphere, it also results in the strengthening of westerly winds through thermal wind balance. Likewise, long-term trends in the Northern Hemisphere (NH) stratospheric dynamics have been identified. $\mathrm{Hu}$ and Tung (2003) detect a significant decline in wave activity in the higher latitudes, which starts from the early 1980s and exists only in late winter and springtime. This is consistent with the findings of Karpetchko and Nikulin (2004) who show a decrease in the vertical propagation of waves into the NH stratosphere in January and February. Additionally, Karpetchko and Nikulin (2004) reveal an increase in the vertical propagation of waves in November and December. A study of the long-term changes in stratospheric wave activity by Kanukhina et al. (2008) indicates an intensification in the stationary planetary wave number 1 activity in the lower stratosphere polar region over the last 40 years. Hu and Tung (2003) propose a similar mechanism as in the SH whereby ozone depletion induces stronger westerly winds which refract planetary waves toward low latitudes and cause the reduction in wave activity in high latitudes. However, Karpetchko and Nikulin (2004) do not find any statistically significant trend in the winter zonal winds. Thus, there is still a lot of uncertainty in the various trends seen in the stratospheric dynamics and the source and mechanism responsible for them.

The aim of this study is to investigate the role of the dynamical forcing in driving the stratospheric zonal-mean flow and its long-term changes, and in particular the dynamical response to long-term changes in stratospheric ozone. For this purpose, we perform a budget analysis of the TransformedEulerian Mean (TEM) formulation of the momentum equation with the European Centre for Medium-Range Weather Forecasts (ECMWF) reanalysis (ERA-40) and with the National Centers for Environmental Prediction (NCEP) Reanalysis 2 (R-2). The TEM formulation offers a useful diagnostic to interpret the forcing of the zonal-mean flow by eddies (Andrews et al., 1983). This work provides a deeper look into the contribution of planetary waves, their stationary and transient components, and of the residual of the momentum equations to the forcing of the stratospheric zonal-mean zonal wind and of the residual mean meridional circulation. Such analysis is vital as the impacts of ozone depletion and wave activity variability on the long-term changes in stratospheric dynamics are not yet fully understood. This paper is organized as follows. The data, the equations and the basic description of the various eddy flux terms involved in the TEM formulation are briefly introduced in Sect. 2. Section 3 describes the climatology of the stratospheric zonal-mean flow and its dynamical forcing, while Sect. 4 presents the results from the trend analysis of the momentum budget. Finally, the discussion and concluding remarks are presented in Sect. 5.

\section{Data and methodology}

\subsection{Data}

In this study, we use the six-hourly ERA-40 reanalysis (Uppala et al., 2005) and secondarily the R-2 reanalysis (Kanamitsu et al., 2002) in order to calculate the various terms involved in the Transformed Eulerian-Mean formulation of the momentum equation. The ERA-40 assimilates nearly all available data into a modern forecast model and provides a complete set of meteorological data, over the whole globe on a $2.5^{\circ} \times 2.5^{\circ}$ grid and over a long time period (1957-2001). Several studies have demonstrated the quality and usefulness of the ERA-40 data in the stratosphere. The annual cycle of the lower stratosphere in the ERA-40 compares well with other reanalysis datasets and the ERA-40 representation of the QBO is excellent up to $10 \mathrm{hPa}$ (Pascoe et al., 2005). The monthly mean ERA-40 temperatures and zonal winds in the lower stratosphere compare well with the NCEP-National Center for Atmospheric Research (NCAR) reanalysis 1 after 1979 (Karpetchko et al., 2005). In addition, Knudsen et al. (2004) show that the ERA-40 winter-averaged polar stratospheric cloud (PSC) areas agree well in most years in the NH with the Free University of Berlin (FUB) analysis, which is largely independent of satellite data. The ERA-40 dataset also shows several weaknesses, such as an enhanced Brewer-Dobson circulation (van Noije et al., 2004; Uppala et al., 2005) or vertically oscillating stratospheric temperature biases over the Arctic since 1998 and over the Antarctic during the whole period (Randel et al., 2004). Also, the ERA-40 reanalysis is unrealistic in the SH stratosphere during the pre-satellite era (Renwick, 2004; Karpetchko et al., 2005). Nonetheless, the ERA-40 reanalysis provides a reasonably reliable dataset in the lower stratosphere during the satellite era. Finally, the R-2 reanalysis provides an independent dataset to address the potential bias in the results of this study associated with the uncertainty in the data used. Because the R-2 reanalysis is only available up to $10 \mathrm{hPa}$, the top level $(10 \mathrm{hPa})$ is disregarded since it can lead to unrealistic behavior for terms involving a vertical centered finite difference. For these reasons, the climatological analysis of the wave forcing of the stratospheric zonal-mean flow is 
performed over the years 1980 to 2001, which coincides with the ozone depletion period, and limited to pressure levels up to $20 \mathrm{hPa}$.

\subsection{Methodology}

\subsubsection{Transformed Eulerian-Mean formulation}

This study uses the Transformed Eulerian-Mean (TEM) formulation of the momentum equation in log-pressure and spherical coordinates in order to accurately diagnose the eddy forcing of the stratospheric zonal-mean flow. In spherical geometry, the TEM zonal momentum equation is (based on Eq. 3.5.2a from Andrews et al., 1987):

$$
\begin{aligned}
& \underbrace{\frac{\partial \bar{u}}{\partial t}}_{\text {Momentum tendency }}=\underbrace{f \bar{v}^{\star}}_{\text {Coriolis }} \underbrace{-\frac{\bar{v}}{a \cos \phi} \frac{\partial}{\partial \phi}(\bar{u} \cos \phi)-\bar{w}^{\star} \bar{u}_{z}}_{\text {force }} \\
& +\underbrace{\frac{1}{\rho_{0} a \cos \phi} \nabla \cdot \boldsymbol{F}}_{\text {Advective terms }}+\underbrace{\bar{X}}_{\text {Residual term }}
\end{aligned}
$$

In Eq. (1) and in the following equations, $u$ is the zonal wind and the terms $\bar{v}^{\star}, \bar{w}^{\star}$ are, respectively, the meridional and vertical components of the residual mean circulation defined by (Eqs. 3.5.1a and b from Andrews et al., 1987):

$$
\begin{aligned}
& \bar{v}^{\star}=\bar{v}-\frac{1}{\rho_{0}} \frac{\partial}{\partial z}\left(\rho_{0} \frac{\overline{v^{\prime} \theta^{\prime}}}{\bar{\theta}_{z}}\right) \\
& \bar{w}^{\star}=\bar{w}+\frac{1}{a \cos \phi} \frac{\partial}{\partial \phi}\left(\cos \phi \frac{\overline{v^{\prime} \theta^{\prime}}}{\bar{\theta}_{z}}\right)
\end{aligned}
$$

where the overbars and primes indicate respectively the zonal means and departures from the zonal mean. $\theta$ is the potential temperature, $v$ is the meridional wind and $w$ is the vertical wind. $\nabla \cdot \boldsymbol{F}$ is the divergence of the Eliassen-Palm (EP) flux vector and represents the divergence of the eddy heat and eddy momentum fluxes. The components of the EP flux vector $\boldsymbol{F}$ are defined by (Eqs. 3.5.3a and b from Andrews et al., 1987):

$$
\begin{aligned}
& \boldsymbol{F}^{(\phi)}=\rho_{0} a \cos \phi\left(\bar{u}_{z} \frac{\overline{v^{\prime} \theta^{\prime}}}{\overline{\theta_{z}}}-\overline{v^{\prime} u^{\prime}}\right) \\
& \boldsymbol{F}^{(z)}=\rho_{0} a \cos \phi\left[\left(f-\frac{1}{a \cos \phi} \frac{\partial}{\partial \phi}(\bar{u} \cos \phi)\right) \frac{\overline{v^{\prime} \theta^{\prime}}}{\bar{\theta}_{z}}-\overline{w^{\prime} u^{\prime}}\right]
\end{aligned}
$$

Finally, $\bar{X}$ represents unspecified horizontal components or friction or other dissipative mechanical forcing (such as subgrid-scale gravity wave drag), and is calculated as the residual of the other terms.

Dunkerton (1978) showed that the Brewer-Dobson (B-D) circulation should be interpreted as a Lagrangian mean circulation and could be approximated by the residual mean meridional circulation of the TEM equations. As a result, the residual mean meridional circulation is often used as a diagnostic for the B-D circulation (Callaghan and Salby, 2002; Nikulin and Karpechko, 2005; Miyazaki and Iwasaki, 2005; Eichelberger and Hartmann, 2005). Thus the various processes forcing the zonal-mean zonal momentum tendency that are investigated in this study are separated into four categories: the Coriolis force due to the B-D circulation, the advection of zonal-mean zonal momentum by the B-D circulation, the divergence of the EP flux or planetary wave forcing, and the residual term. Additionally, when we refer to the EP flux divergence, or $\nabla \cdot \boldsymbol{F}$, we indicate the EP flux forcing term in Eq. (1), including the weight by the density, the Earth's radius and cosine of latitude. The signs shown in Eq. (1) are included in the various displayed terms. Each term is calculated using the six-hourly ERA-40 and R-2 datasets and centered finite differences.

\subsubsection{Stationary and transient components}

Because stratospheric dynamics are primarily driven by planetary waves, whether directly or indirectly, it is useful to decompose the zonal momentum forcing into contributions from stationary and transient waves. Stationary planetary waves are excited by the orography (Charney and Eliassen, 1949), especially in the $\mathrm{NH}$, as well as by land-sea heating contrasts, which vary on the seasonal time scale. Planetary transient waves, on the other hand, have smaller time scales ranging from a few days to a couple of weeks and dominate synoptic weather patterns. The stationary components are computed by averaging temperature and wind fields over a month and then calculating the various terms of the TEM formulation. Once the stationary component is removed from the total term, which is calculated every six hours, only the contribution from the transient waves is left (Madden and Labitzke, 1981).

\section{Climatology of the stratospheric zonal-mean flow}

\subsection{Seasonal cycle of the zonal momentum budget}

Figure 1 presents the annual cycle of the ERA-40 zonalmean zonal wind, its tendency and forcing terms, averaged between 100 and $20 \mathrm{hPa}$ for the 1980-2001 period. The annual cycle of the zonal flow shows distinct and well-known features such as the wintertime stratospheric polar night jets, strongest in the $\mathrm{SH}$, and the latitudinal migration of the stratospheric tropical easterlies with the seasons (Oort, 1983; Andrews et al., 1987; McWilliams, 2006). In the NH, the maximum in the stratospheric polar vortex westerlies occurs from December to February and is centered on $60^{\circ} \mathrm{N}$, while weak easterlies are present from May to July. In the SH, the maximum in the westerlies occurs later in the winter than in the $\mathrm{NH}$, from July to September, and is centered on $60^{\circ} \mathrm{S}$. 

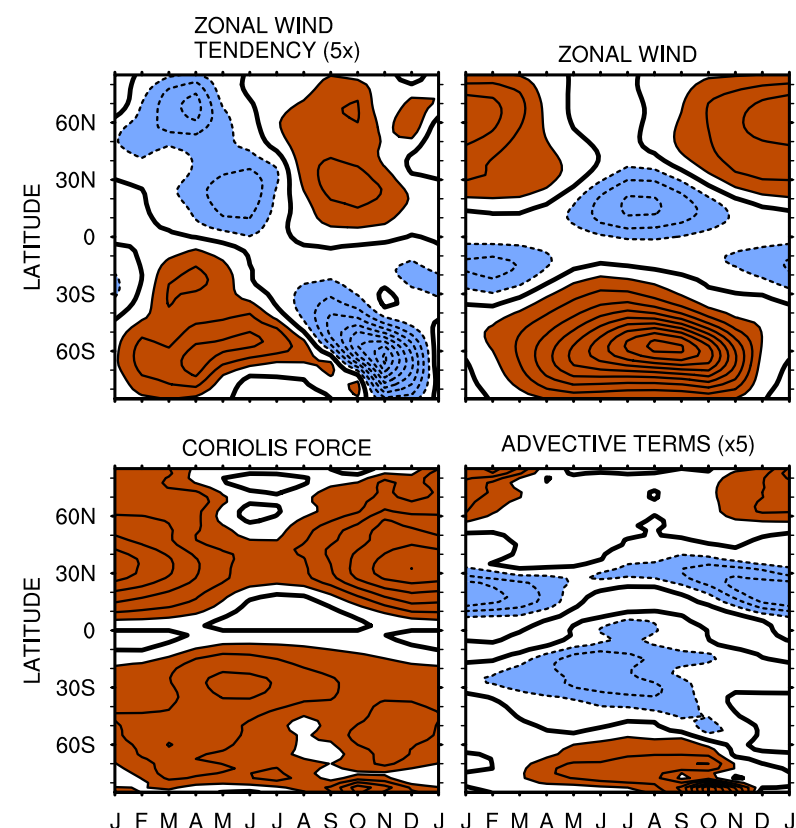

ADVECTIVE TERMS $(x 5)$
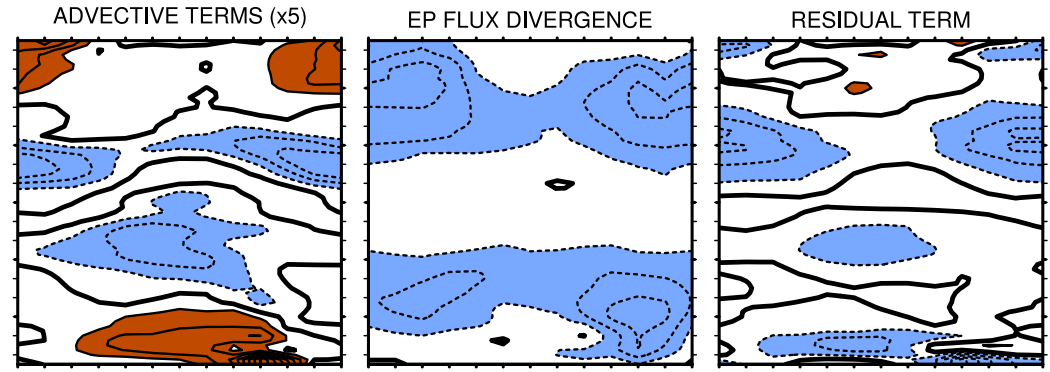

MONTH

MONTH

MONTH

MONTH

Fig. 1. Annual cycle of the ERA-40 stratospheric zonal-mean zonal wind, zonal wind tendency and each forcing term in the TEM momentum equation averaged between 100 and $20 \mathrm{hPa}$. Dashed (solid) lines and blue (brown) shadings represent negative (positive) values while the bold solid line represent the zero-line. Contour interval is $6 \mathrm{~m} \mathrm{~s}^{-1}$ for the zonal wind and $0.5 \mathrm{~m} \mathrm{~s}^{-1}$ day $^{-1}$ for the zonal wind tendency and forcing terms. Note that the zonal wind tendency and advective terms are weak compared to the other terms and are therefore multiplied by 5 .

The zonal momentum tendency displays a clear seasonal cycle in the $\mathrm{NH}$ with an increase from July to December and a decrease from January to June with two distinct peaks (in the polar region and in the subtropics). In the $\mathrm{SH}$, the momentum tendency presents a more complex structure with an increase lasting longer than in the $\mathrm{NH}$, from January to August and a brief and intense decrease from September to December taking place mainly in the midlatitudes and polar region.

The Coriolis force due to the B-D circulation is characterized by an eastward forcing all year long except right along the Equator where its forcing is close to zero. The Coriolis force displays a pronounced seasonal cycle in the $\mathrm{NH}$ with a broad maximum in the midlatitudes from November to January and a minimum in June and July. In the SH, the Coriolis forcing presents two distinct peaks, weaker than in the $\mathrm{NH}$, a brief and sharp maximum centered on $60^{\circ} \mathrm{S}$ from October to December and the other in the subtropics from May to July. Although much weaker than the other forcing terms, the advection of zonal momentum by the B-D circulation shows a clear seasonal cycle with the strongest forcing occurring in the wintertime. The advective terms correspond to an eastward forcing in the polar region and a westward forcing in the tropics in both $\mathrm{SH}$ and $\mathrm{NH}$. The EP flux converges over most of the year and domain resulting in a continuous westward forcing, strongest in the midlatitudes and present in both hemispheres. A broad maximum in the EP-flux convergence is present from early winter until late spring in the
$\mathrm{NH}$ and a sharp and brief peak is present in spring in the SH. Finally, the residual term contributes to a westward forcing during wintertime in the subtropics and polar regions. The R-2 generally agrees well with the ERA-40 reanalysis, in particular for the zonal wind, its tendency and the EP flux divergence (see Supplement, Fig. S1). Some discrepancies include the R-2 Coriolis force displaying little latitudinal migration with the seasons in the $\mathrm{SH}$, and the $\mathrm{R}-2$ residual term being close to zero in the polar regions in both hemispheres.

The fact that the forcing of the stratospheric zonal wind takes place mainly in wintertime, particularly in the $\mathrm{NH}$, is consistent with the finding of Charney and Drazin (1961) who showed that planetary Rossby waves can only propagate upward toward the stratosphere when the zonal wind is westerly but not too strong, which occurs in the wintertime in the $\mathrm{NH}$. In the SH winter, the westerly winds are much stronger than in the $\mathrm{NH}$ and as a result they inhibit the vertical propagation of planetary waves into the stratosphere. This leads to a delay in the forcing of the stratospheric zonal wind. The convergence of EP flux, which represents the westward force on the zonal-mean flow due to vertically propagating planetary waves breaking and dissipating into the stratosphere, is primarily responsible for the deceleration of the polar night jets. This deceleration is partially balanced by the Coriolis force due to the B-D circulation. While the advective terms have small magnitudes compared to the EP flux and Coriolis terms, they have the same magnitude as the zonal momentum 

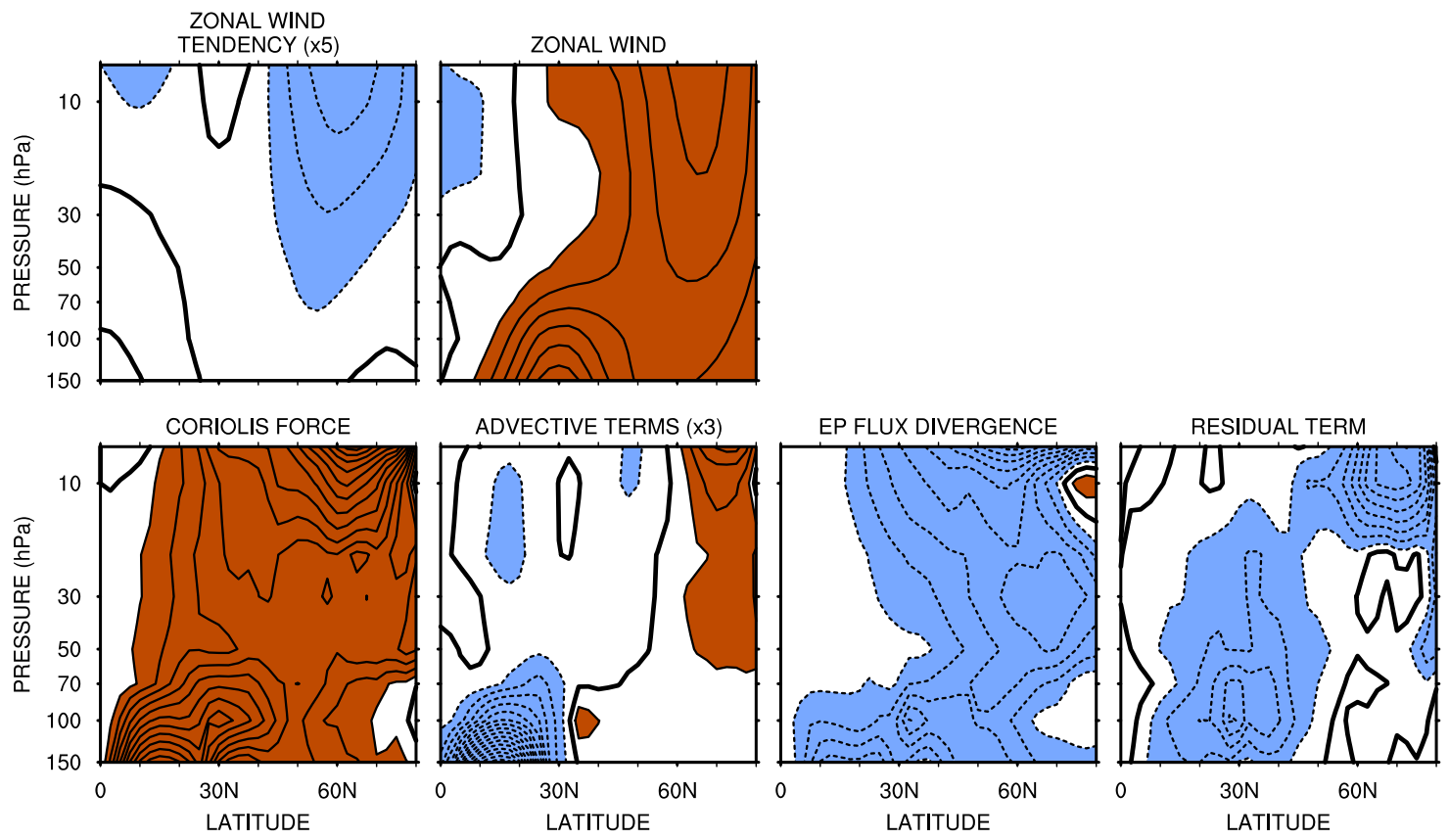

Fig. 2. Latitude-height cross-sections of the zonal-mean zonal wind, zonal wind tendency and its forcing terms in the Northern Hemisphere averaged over JFM 1980-2001 for the ERA-40 reanalysis. Dashed (solid) lines and blue (brown) shadings represent negative (positive) values while the bold solid line represent the zero-line. Contour interval is $6 \mathrm{~m} \mathrm{~s}^{-1}$ for the zonal wind and $0.5 \mathrm{~m} \mathrm{~s}^{-1}$ day ${ }^{-1}$ for the zonal wind tendency and forcing terms. Note that the zonal wind tendency and advective terms are weak compared to the other terms and are therefore multiplied by 5 and 3 respectively.

tendency and thus cannot be entirely neglected. Finally, the residual term displays magnitudes similar to the EP flux term, particularly in the NH wintertime, and thus contributes significantly to the momentum budget.

\subsection{Vertical structure of the zonal momentum budget}

An example of the vertical structure of the ERA-40 zonalmean zonal wind, its tendency and forcing terms for the months of January-February-March (JFM) in the NH, when the polar vortex is breaking down, is presented in Fig. 2. The mean zonal winds exhibit strong westerlies in the subtropical lower stratosphere, corresponding to the top of the subtropical jet stream, and in the middle stratosphere over the subpolar region, where the stratospheric polar night jet is located. At the same time, the zonal momentum tendency shows a deceleration of the strong westerlies in the polar region, leading to the break down of the polar vortex. Figure 2 shows that the EP flux converges over the whole region leading to a deceleration of the zonal-mean zonal wind, strongest in the subtropical lower stratosphere and subpolar middle stratosphere. This deceleration is largely balanced by the Coriolis force. The relatively small impact of the advective terms is mainly confined to the middle stratosphere in the polar region and to the tropics below $70 \mathrm{hPa}$. Finally, the residual term presents a clear deceleration in the latitude band between $20^{\circ}-40^{\circ} \mathrm{N}$ centered around $100 \mathrm{hPa}$ with a maximum of around $2 \mathrm{~m} \mathrm{~s}^{-1} \mathrm{day}^{-1}$. It also shows a strong deceleration in the middle stratosphere polar region which reaches $3 \mathrm{~m} \mathrm{~s}^{-1}$ day $^{-1}$ near $10 \mathrm{hPa}$. The magnitudes of these values confirm that the residual term plays a role in the momentum budget, and thus requires further interpretation. The R-2 reanalysis agrees generally well with the ERA- 40 up to $20 \mathrm{hPa}$, the major differences taking place in the polar region where the R-2 forcing terms tend to be slightly weaker than in the ERA-40 (see Supplement, Fig. S2).

\subsection{Residual term}

The residual term may be interpreted as friction and any wave forcing not included in the divergence of the EP flux, such as gravity wave drag or other unresolved processes. In the ERA-40 model, the influence of subgrid-scale orography on the momentum of the atmosphere is represented by a combination of lower-tropospheric drag created by orography, and of vertical profiles of drag due to the absorption and reflection of vertically propagating gravity waves generated by stably stratified flow over the subgrid-scale orography (Lott and Miller, 1997). Similarly, Kanamitsu (1989) states that the NCEP model evaluates the effects of gravity wave drag generated by the orography in the stably stratified boundary layer along with a vertical distribution of the drag based on Palmer et al. (1986), Pierrehumbert (1986) and Helfand et al. (1987). Several studies have estimated the stratospheric 
a) ERA40 RE-ANALYSIS
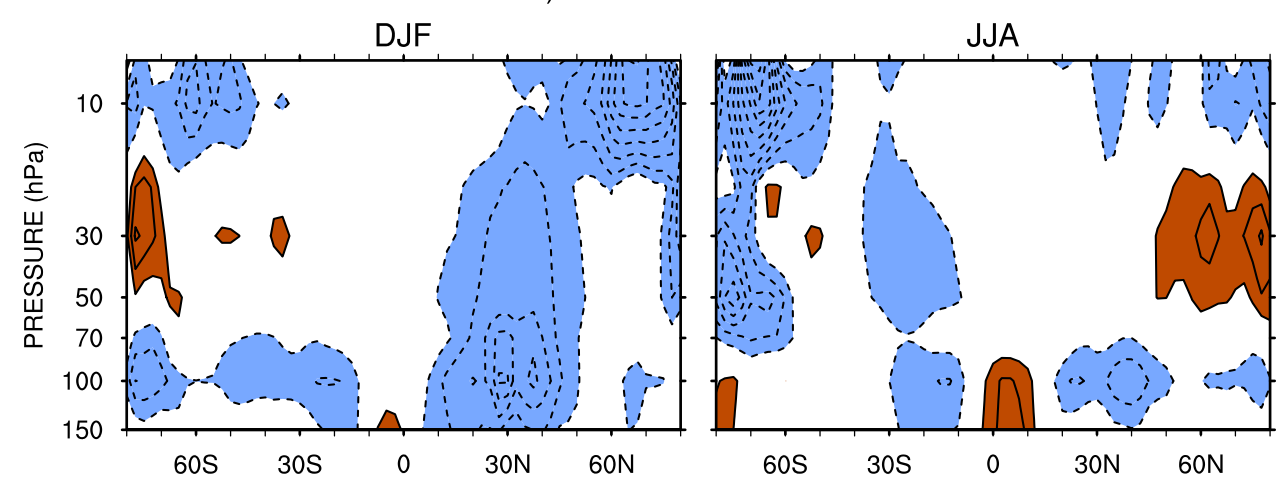

b) NCEP RE-ANALYSIS 2
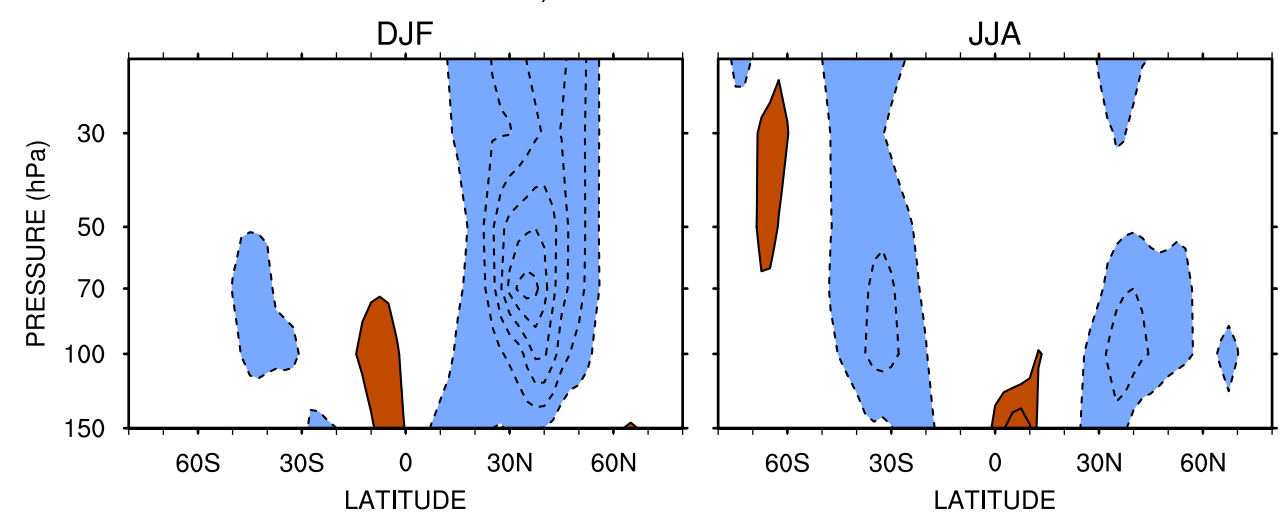

Fig. 3. Latitude-height cross-sections of the residual term in the TEM momentum equation averaged over DJF and JJA for the ERA-40 and R-2 reanalyses. Note that the R-2 reanalysis residual term is only shown up to 20-hPa. Dashed (solid) lines and blue (brown) shadings represent negative (positive) values. Contour interval is $0.5 \mathrm{~m} \mathrm{~s}^{-1} \mathrm{day}^{-1}$.

gravity wave drag as the residual term from the momentum equation (Hartmann, 1976; Hamilton, 1983; Smith and Lyjak, 1985; Alexander and Rosenlof, 1996, 2003). Alexander and Rosenlof (2003) estimate the gravity-wave driven forcing in the stratosphere from November 1991 to June 1997 as the residual from the TEM equations using data from the Upper Atmosphere Research Satellite (UARS) and the UK Met Office (UKMO). They show that with some averaging of the gravity wave drag estimates, the seasonal cycles are robust, and the magnitudes are reliable within approximately a factor of 2. Based on these previous studies, it seems reasonable to assume that the residual term is indeed representative a stratospheric gravity wave drag, though this needs to be confirmed.

Figure 3 shows the height-latitude profiles of the residual term for the winter and summer seasons for both the ERA-40 and R-2 reanalyses. Note that the R-2 residual term is only displayed up to $20 \mathrm{hPa}$ because the $\mathrm{R}-2$ reanalysis is only available up to $10 \mathrm{hPa}$ and the top level should be disregarded for terms involving vertical centered finite differences. Overall, the residual terms calculated with the two independent reanalyses broadly agree outside of the po- lar regions. Both residual terms are large during winter and generally negative while they are much weaker during summer, mainly because all the terms in the TEM momentum equation are small. In the NH winter, the local maximum located just above the subtropical jet stream near $100 \mathrm{hPa}$ and between $30^{\circ}-40^{\circ} \mathrm{N}$, with decelerations of $2 \mathrm{~m} \mathrm{~s}^{-1} \mathrm{day}^{-1}$, is in agreement with previous analyses and modeling studies (Palmer et al., 1986; Scinocca and McFarlane, 2000; McFarlane, 2000) and radar measurements (Fritts and Alexander, 2003). A second local maximum is present in the ERA40 , in the middle to upper stratosphere in the polar region with decelerations greater than $3 \mathrm{~m} \mathrm{~s}^{-1}$ day $^{-1}$ near $10 \mathrm{hPa}$. Because this second peak in the residual term takes place above $20 \mathrm{hPa}$, it cannot be investigated in the R-2 dataset. Nonetheless, such deceleration in the polar region is within the range of gravity wave drags parameterized in modeling studies (Smith and Lyjak, 1985; Scinocca and McFarlane, 2000; McFarlane, 2000; Mieth et al., 2004; Richter et al., 2008). In the SH winter, the subtropical maximum is weaker than in the $\mathrm{NH}$, primarily because of the comparative lack of topography. The ERA-40 residual term presents a distinct deceleration in the polar region that extends into the 


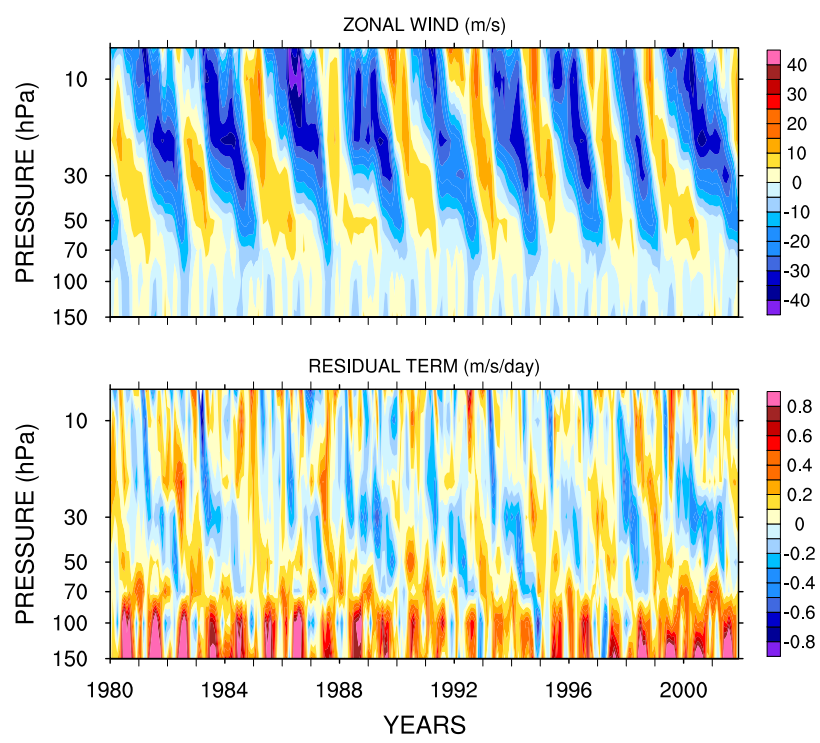

Fig. 4. Hovmöller diagram of the equatorial (averaged between $\left.10^{\circ} \mathrm{S}-10^{\circ} \mathrm{N}\right)$ zonal-mean zonal wind $\left(\mathrm{m} \mathrm{s}^{-1}\right)$ and of the residual term $\left(\mathrm{m} \mathrm{s}^{-1}\right.$ day $\left.^{-1}\right)$.

lower stratosphere, in agreement with Scinocca and McFarlane (2000) and Alexander et al. (2010). On the other hand, the R-2 residual term shows a weak acceleration. As such, there is some disagreement between the two reanalyses in the polar region, in particular in the $\mathrm{SH}$ winter. While there is some disparity between the residual terms calculated from the two independent reanalyses, they show some consistent characteristics associated with a gravity wave drag.

Focusing on the tropics, Fig. 4 shows the ERA-40 residual term and zonal-mean zonal wind averaged over the equatorial latitude band $10^{\circ} \mathrm{S}-10^{\circ} \mathrm{N}$ as a function of height and time. Tongues of eastward acceleration from the residual term descend in time and lead the eastward wind phase of the Quasi Biennial Oscillation (QBO) by about 3 to 5 months. Similarly, a deceleration by the residual term occurs during the descent of the westward QBO phase. As such, the residual term is consistent with the tropical gravity wave forcing of the QBO and is comparable to numerous analyses and global model studies (Dunkerton, 1997; Scaife et al., 2002; Alexander and Rosenlof, 2003). The R-2 residual term over the tropics (see Supplement, Fig. S3) also shows a clear QBO signal. Finally, an analysis of the seasonal cycle of the tropical residual term (see Supplement, Fig. S4 and Fig. S5) reveals a migration of its maximum with latitudes across the Equator between boreal and austral summers, following the Inter-Tropical Convergence Zone (ITCZ). The 22 -yr mean residual term exhibits positive values in winter and summer, which correspond to a deceleration of the zonal-mean zonal wind since the prevailing winds are easterly in the tropical region. In January, the drag force is located south of the Equator while it is located north of the
Equator in July, with magnitudes of the deceleration reaching up to $0.5 \mathrm{~m} \mathrm{~s}^{-1} \mathrm{day}^{-1}$ in both reanalyses. This result is in agreement with Chun et al. (2004) who introduces a parameterization scheme of gravity wave drag induced by cumulus convection in the National Center for Atmospheric Research Community Climate Model (NCAR CCM3).

The uncertainties in the residual term in this analysis are difficult to quantify, partly because there are no global observations of gravity wave drag. Notably, there exists considerable discrepancy in the representation of the B-D circulation among the various reanalyses currently available, especially in low latitudes (Randel et al., 2008; Iwasaki et al., 2009). So while it is valid to use the ERA-40 and R-2 reanalyses for the demonstration of the method, the residual term might be dependent on the presence of biases in the datasets and should eventually be compared to results from other datasets. Nonetheless, the seasonal cycle and magnitudes of the residual terms in both reanalyses are indeed consistent with gravity wave drags used in various studies. As a simple test of the possible influence of the known overestimate of the B-D circulation in the ERA-40 reanalysis, we recalculated the budget assuming a decrease in $\bar{v}^{\star}$ and $\bar{w}^{\star}$ of $25 \%$. The resultant figures, comparable to Fig. 3, are qualitatively nearly identical with slight decreases in magnitude of less than $20 \%$. Furthermore, the estimation of unresolved processes as the residual term in the TEM momentum equation is likely to be an improvement over many studies where the effects of unresolved waves are crudely parameterized using a simple Rayleigh friction coefficient (Schoeberl and Strobel, 1978; Holton and Wehrbein, 1980; McLandress, 1998; Seol and Yamazaki, 1999), thus assuming a deceleration linear to the mean zonal wind. Shepherd and Shaw (2004) suggest that a Rayleigh friction introduces a nonphysical momentum sink and Haynes (2005) finds it difficult to argue that such a friction is at all relevant in the stratosphere.

\subsection{EP flux divergence}

While the residual term seems to contribute to the momentum budget in specific regions of the stratosphere, the main forcing in the deceleration of the zonal wind in the $\mathrm{NH}$ winter and $\mathrm{SH}$ late spring is the EP flux divergence. An example of the vertical structure of the EP flux vector, the EP flux divergence and its horizontal and vertical components for JFM is shown in Fig. 5 for the ERA-40 reanalysis. A distinct property of the EP flux divergence is the competition between its two components, which largely cancel each other in the extratropics. $\nabla \cdot \boldsymbol{F}^{(\phi)}$ is dominated by the horizontal divergence of the meridional eddy momentum flux and $\nabla \cdot \boldsymbol{F}^{(z)}$ is controlled by the vertical divergence of the meridional eddy heat flux (Andrews et al., 1987). Figure 5 underlines the fact that while the eddy momentum flux and eddy heat flux have contributions of opposite sign, they do not act separately but in combination, with a net impact resulting in a westward body force that decelerates the polar vortex in the NH wintertime. 

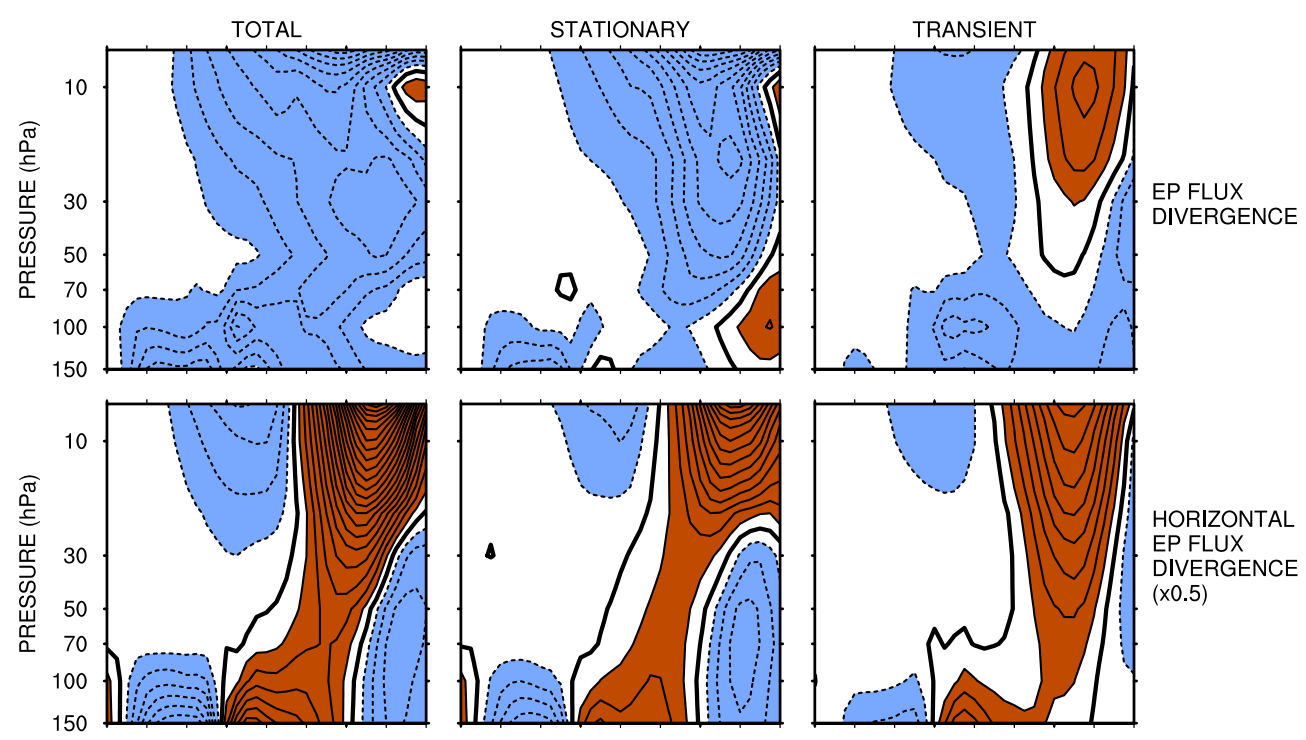

HORIZONTAL

EP FLUX

DIVERGENCE
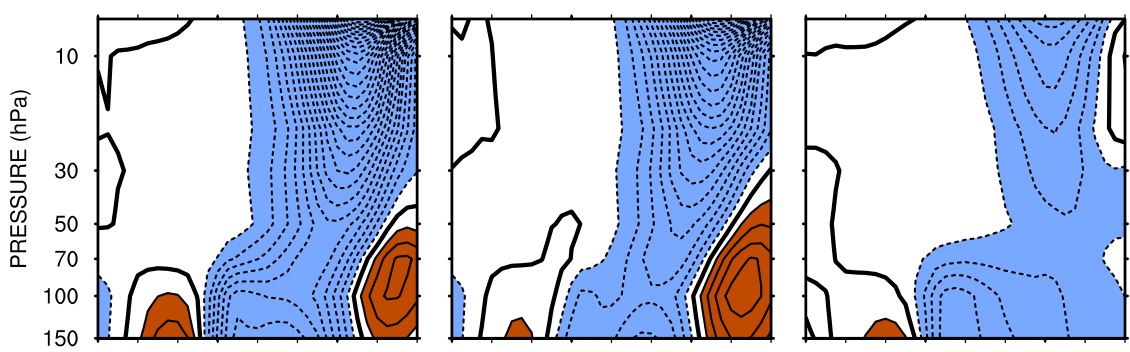

VERTICAL

EP FLUX

DIVERGENCE
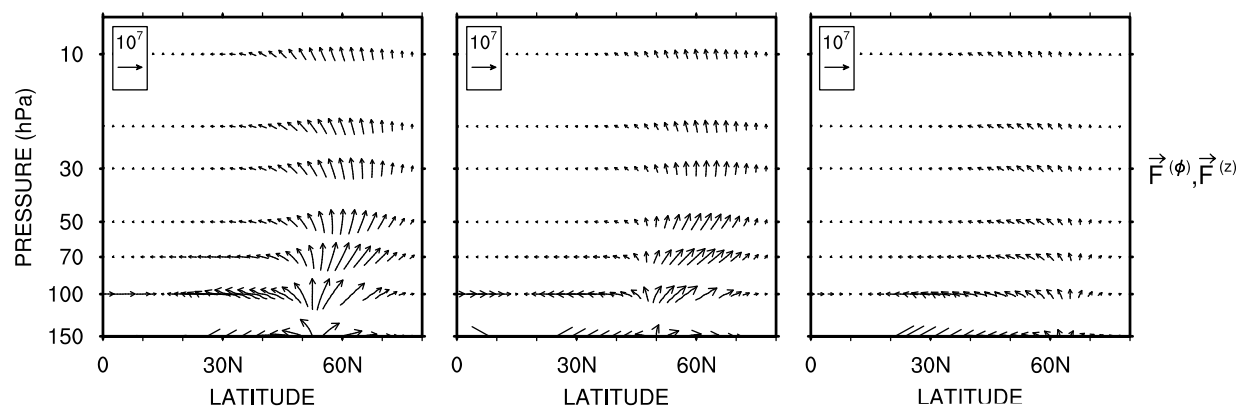

Fig. 5. Same as Fig. 2 but for the EP flux divergence, its horizontal and vertical components, and the EP flux vector, including stationary and transient components. Contour interval is $0.5 \mathrm{~m} \mathrm{~s}^{-1} \mathrm{day}^{-1}$ for the EP flux divergence and its horizontal and vertical components. The reference vector corresponds to $10^{7} \mathrm{~kg} \mathrm{~s}^{-2}$ and the vertical component is multiplied by 100 for scaling purposes. Note that the horizontal and vertical components of the EP flux divergence are large compared to the EP flux divergence and are therefore multiplied by 0.5 .

In addition, the presence of a greater land area and topography distribution in the $\mathrm{NH}$ results in a stronger contribution from stationary processes, which are forced by topography and land-sea heating contrasts. However, the transient contribution is not negligible. The main difference between the stationary and transient components resides in the presence of a distinct divergence of the transient EP flux in the polar region middle stratosphere. This feature is also present in the EP flux divergence calculated using the R-2 reanalysis, which compares well with the ERA-40 reanalysis (see Supplement, Fig. S6).
The EP flux vector $\boldsymbol{F}$ is a useful diagnostic tool for the net propagation of wave energy by planetary waves from one region, at one latitude and one height, to another. Under the WKBJ (Wentzel-Kramers-Brillouin-Jeffreys) approximation and when dealing with planetary waves with small latitudinal and vertical wavelength, it can be shown that the EP flux vector is proportional to the local group velocity projected onto the meridional plane (Edmon Jr et al., 1980). Figure 5 indicates that, in the $\mathrm{NH}$ wintertime, the vertical component of the EP flux vector, dominated by the meridional eddy heat flux, is oriented upward indicating the vertical propagation of planetary wave energy into the stratosphere. The vertical 

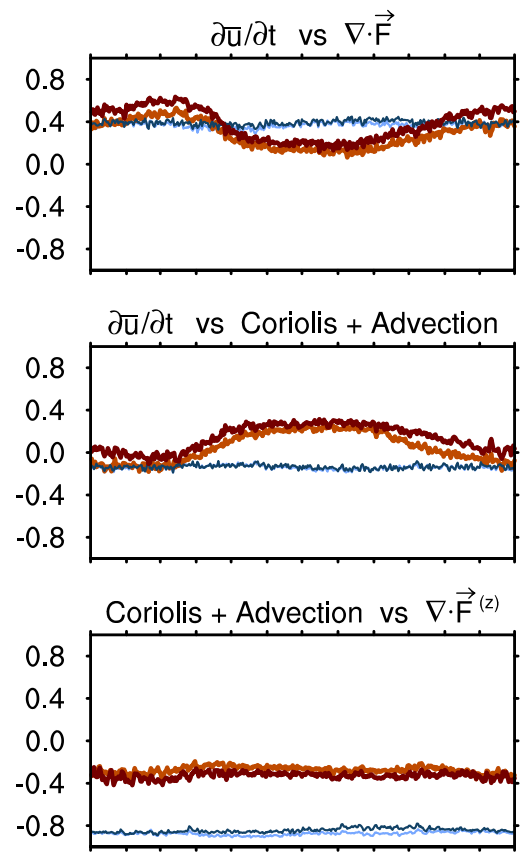

JFMAM J JASOND MONTH
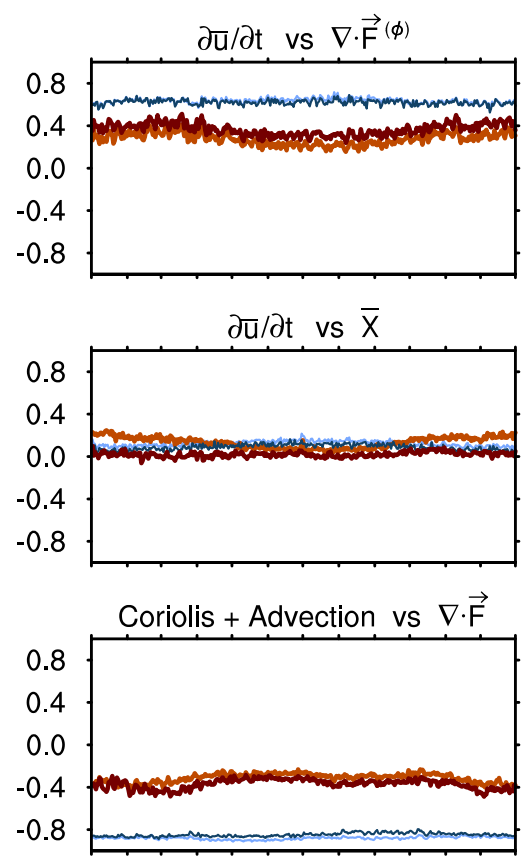

J F M A M J J A SOND MONTH
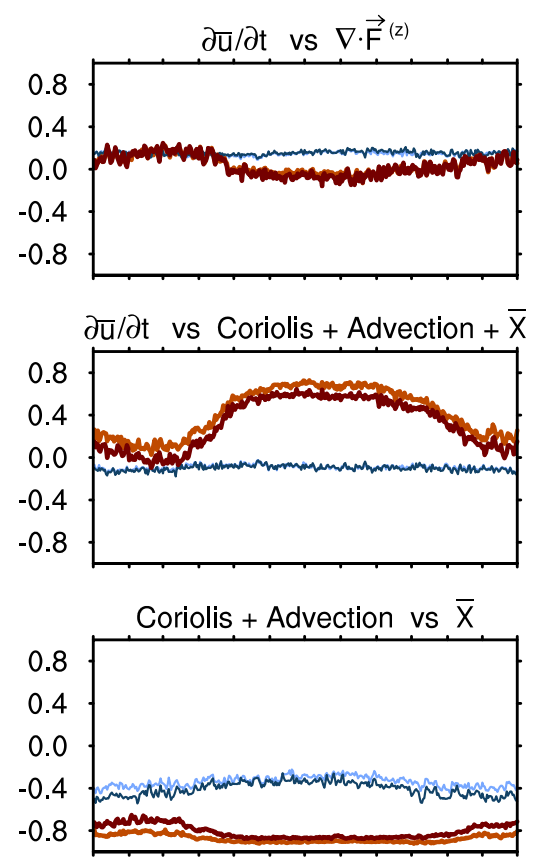

J F M A M J JASOND MONTH

Fig. 6. Time variations of spatial correlation coefficients over the Northern Hemisphere in the troposphere (blue lines), up to $250 \mathrm{hPa}$, and in the stratosphere (brown lines), between 150 and $20 \mathrm{hPa}$, between the various terms of the TEM momentum equation for the ERA-40 (light) and R-2 (dark) reanalyses. Correlation coefficients are calculated every $6 \mathrm{~h}$ over the time period 1 Jan 1980-31 Dec 2001.

component also decreases with height, leading to a net convergence. Concurrently, the horizontal component of the EP flux vector shows that planetary waves propagating into the stratosphere are bent away from the stratospheric polar night jet, toward the Equator at midlatitudes and toward the pole in the lower stratosphere polar region. This leads to a strong divergence of the meridional eddy momentum flux superposed onto the location of the strong westerlies. Consequently, the cancellation between the components of the EP flux divergence is the result of the refraction of planetary waves around the stratospheric polar night jet. Indeed, the effective index of refraction for the planetary waves depends primarily on the distribution of the zonal mean wind with height and energy can be refracted in regions where the zonal wind is westerly and large, like the stratospheric polar night jet (Charney and Drazin, 1961).

A similar analysis of the EP flux terms for the SH reveals that the main difference compared to the $\mathrm{NH}$ is the stronger contribution of transient wave forcing. The contribution of stationary processes is mostly limited to the polar region, where the presence of the asymmetric Antarctic topography and ice-sea heating contrasts drives stationary wave activity (Parish et al., 1994; Lachlan-Cope et al., 2001). Overall, the analysis of the EP flux shows that both stationary and transient planetary waves contribute to the propagation of wave energy into the stratosphere. It also suggests a complex in- terplay between the eddy momentum and eddy heat fluxes in the stratosphere in the overall driving of the zonal-mean zonal wind.

\subsection{Correlations of zonal momentum forcing}

To gain more insight into the relative contributions of the forcing terms to the zonal wind variability, spatial correlation coefficients between the forcing terms are calculated and shown in Fig. 6 for both the ERA-40 and R-2 datasets. This analysis is similar to the statistics presented in Pfeffer (1992), but is extended to a 22-yr daily climatology and includes an analysis of the stratosphere. It also focuses on one hemisphere at a time to account for the strong seasonality of the wave-mean flow interaction in the stratosphere. In the stratosphere, the correlation coefficients present a strong seasonality due to the absence of planetary wave propagation into the stratosphere at midlatitudes in summer. Figure 6 reveals that, contrary to the troposphere where the zonal momentum tendency is highly correlated with $\nabla \cdot \boldsymbol{F}^{(\phi)}$ but not with $\nabla \cdot \boldsymbol{F}^{(z)}$, the zonal momentum tendency in the stratosphere is better correlated with the divergence of the EP flux than with either of the contributions from its separate components. This confirms that the eddy momentum and eddy heat fluxes in the stratosphere act in combination to drive the zonal-mean zonal wind. The correlations between the momentum tendency 

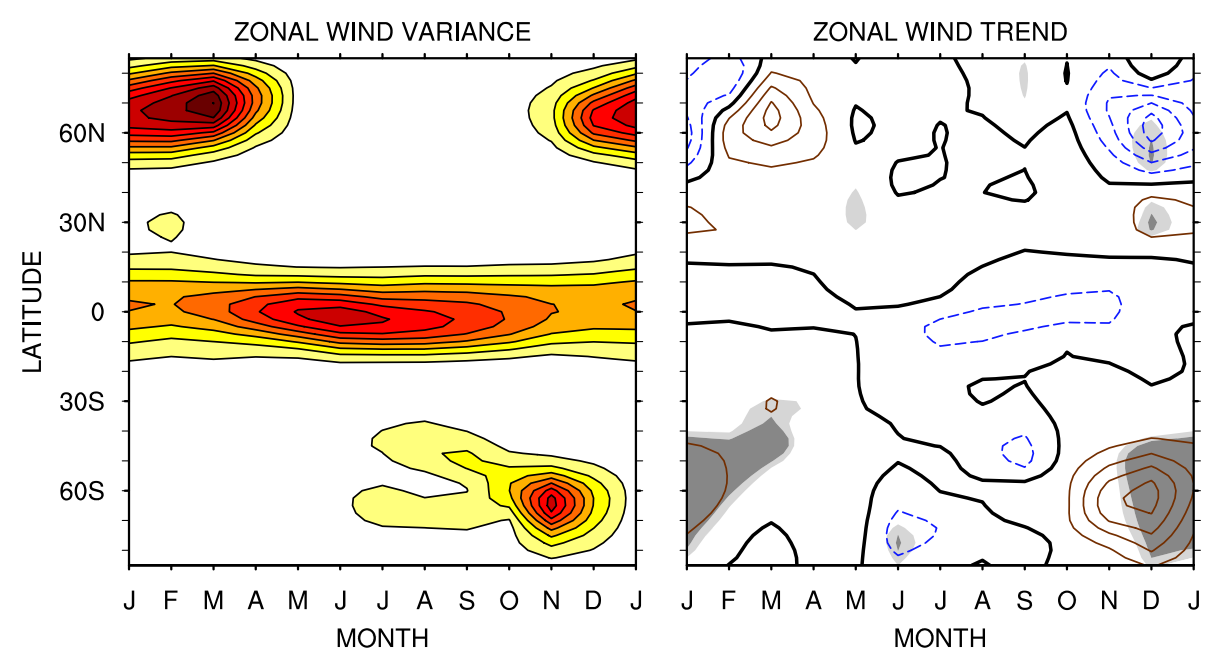

Fig. 7. Annual cycle of the zonal wind sample variance and trend. The variances and trends are calculated after the zonal wind is averaged between 100 and $20 \mathrm{hPa}$. Dashed blue (solid brown) lines represent negative (positive) trends while the bold solid line represents the zeroline. Light grey (dark grey) shadings represent the $90 \%$ (95\%) statistical significance level of the trends. Contour interval is $10 \mathrm{~m}^{2} \mathrm{~s}^{-2}$ for the variances and $1 \mathrm{~m} \mathrm{~s}^{-1}$ per decade for the trends.

and the EP flux divergence are strongest in March in the NH stratosphere, where they reach 0.5. Meanwhile, the momentum tendency is highly correlated with the sum of the Coriolis, advective and residual terms in the summertime, with correlations above 0.7 , but not with each individual terms. In the troposphere, the Coriolis and advective terms exhibit a high negative correlation with $\nabla \cdot \boldsymbol{F}^{(z)}$, reflecting the fact that the wave drag exerted by $\nabla \cdot \boldsymbol{F}^{(z)}$ is consumed by driving the residual circulation. However, in the stratosphere, the Coriolis and advective terms are poorly correlated with $\nabla \cdot F^{(z)}$ or even $\nabla \cdot \boldsymbol{F}$, with a maximum correlation near 0.4 during winter. Instead they show a high negative correlation with the residual term, reaching a maximum of 0.8 from spring to fall when the EP flux divergence is weak. This suggests that in the Northern Hemisphere, unresolved forces, such as subgrid-scale gravity waves, contribute substantially to driving the B-D circulation. The same analysis was done for the Southern Hemisphere and yields similar results.

It is important to note that the B-D circulation is a non local response to wave driving and that downward control implies that the vertical velocities at a specific level are controlled exclusively by the wave forcing above that level (Haynes et al., 1991). This is likely to affect the physical significance of the correlations between the Coriolis and advective terms and the wave forcing terms. Furthermore, the uncertainties in the residual term due to the B-D circulation bias in the ERA- 40 can contribute to the strong anticorrelation between the residual term and the Coriolis and advective terms. Nonetheless, the statistics derived from the ERA-40 and R-2 reanalyses show a remarkable agreement, in particular in the high (negative) correlation between the Coriolis term and the residual term. This suggests that the contribution of noise or bias (such as the enhanced B-
D circulation in the ERA-40) to the residual term is small. As such, this result strengthens the suggestion that gravity wave drag plays a considerable role in driving the B-D circulation, which has been evidenced in several studies based on the analysis of climate-chemistry model simulations ( $\mathrm{Li}$ et al., 2008; McLandress and Shepherd, 2009; Butchart et al., 2010).

\section{Trends in the wave forcing of the stratospheric zonal-mean momentum}

\subsection{Zonal-mean zonal wind}

The long-term trends and interannual variability of the lower and middle stratosphere zonal-mean zonal wind are investigated in Fig. 7 for the ERA-40. The same analysis was performed using the R-2 reanalysis and yielded very similar results. The variances and trends are calculated after the zonal-mean zonal wind is averaged between 100 and $20 \mathrm{hPa}$. In the tropics, the zonal wind displays a large variance representing a strong interannual variability all year long, which corresponds to the Quasi-Biennial Oscillation (QBO). The tropical variability shows a maximum in variance during the $\mathrm{NH}$ late spring, which is consistent with the fact that the onset of both easterly and westerly QBO phases occurs mainly during NH late spring at the $50 \mathrm{hPa}$ level (Dunkerton, 1990; Baldwin et al., 2001). Outside the tropics, the zonal wind variance is large in the polar region from early winter until early spring in the $\mathrm{NH}$ and limited to the late spring in the $\mathrm{SH}$, which is likely associated with the breakdown of the polar vortex. The trend analysis reveals a long-term increase in the SH zonal wind from November to January, which is 
only statistically significant in December and January. This indicates that the SH polar vortex tends to persist longer into the summer, towards the end of the analysis period. In particular, the SH zonal wind has increased in December at a rate of $3.5 \mathrm{~m} \mathrm{~s}^{-1}$ per decade and at a $99 \%$ significance level (calculated using a two-tailed Student's $t$-test). This result is in agreement with several studies (Thompson and Wallace, 2000; Thompson and Solomon, 2002; Renwick, 2004; Karpetchko et al., 2005). Several of the later years (1998, 1999 and 2001) display strong westerlies close to $10 \mathrm{~m} \mathrm{~s}^{-1}$ in December, compared to the 22-yr mean that is close to zero. In the $\mathrm{NH}$, negative trends in the zonal wind are present in the late fall and early winter. However, these negative trends are only statistically significant in December, when the zonal wind has weakened at a rate of over $4 \mathrm{~m} \mathrm{~s}^{-1}$ per decade, with a $95 \%$ statistical significance level. Meanwhile, positive trends occur from February to March, during the breakdown of the polar vortex, however they are not statistically significant. For example, the March westerlies have strengthened, at a rate close to $3 \mathrm{~m} \mathrm{~s}^{-1}$ per decade, with a $87 \%$ significance level. While that trend shows only a moderate statistical significance in this analysis, it is similar to results by Thompson and Wallace (2000) who show that the westerlies near $55^{\circ} \mathrm{N}$ have increased by as much as $10 \mathrm{~m} \mathrm{~s}^{-1}$ over $30 \mathrm{yr}(1968-$ 1997 ) at $50 \mathrm{hPa}$. Overall, the trends in the $\mathrm{NH}$ zonal-mean zonal winds indicate a temporal shift in the timing of the $\mathrm{NH}$ polar vortex that seems to be pushed further into the wintertime.

\subsection{Wave forcing of zonal momentum budget}

From the previous trend analysis, it is evident that the regions of interest to carry out a trend analysis of the stratospheric zonal momentum budget are the polar regions, in particular the latitude bands between $50^{\circ}-80^{\circ}$. Furthermore, the trends in the zonal-mean zonal wind displays a strong seasonality associated with a lack of stratospheric planetary wave activity in summer. For this reason it is important to investigate the seasonality of long-term changes in the zonal momentum budget. In order to identify the months when there is good agreement between the ERA-40 and R-2 reanalyses, we calculate the 22-yr means of the momentum tendency and its forcing terms, averaged between 100 and $20 \mathrm{hPa}$ and between $50^{\circ}-80^{\circ}$, as well as the temporal correlations between the two datasets (see Table 1 and Fig. 8). This analysis reveals that there is a very good agreement between the two independent datasets for the momentum tendency and EP flux divergence, in both magnitudes and variability. In particular, the correlations between the ERA- 40 and R-2 is above 0.90 for the momentum tendency for each month of the year over both hemispheres. Meanwhile, the correlations for the EP flux divergence are above 0.80 during the $\mathrm{NH}$ winter and spring and during the $\mathrm{SH}$ late spring and early summer. They tend to be a bit weaker but still statistically significant in the $\mathrm{NH}$ summer and fall (between 0.60 and 0.90 ) when planetary wave activity is weak. In addition, the EP flux divergence in the SH winter and fall exhibits a much weaker correlation between the two reanalyses, but the long-term means are not statistically different. The ERA- 40 and R-2 Coriolis and advective terms also show good agreement in the $\mathrm{NH}$ winter and spring, when the planetary wave activity is at its peak. However, there is very little agreement in the means and correlations of the Coriolis and advective terms between the ERA-40 and R-2 reanalyses in the NH in summer and early fall and in the SH most of the year. Finally, the 22-yr means of the residual term in the two datasets are not statistically different in the $\mathrm{NH}$ winter and spring and in the SH late spring and summer, although they exhibit poor correlations. Based on this analysis, trend analyses of the momentum tendency and EP flux divergence should yield consistent results over all seasons between the ERA-40 and NCEP reanalyses. However, the trends in the Coriolis and residual terms should be regarded as greatly uncertain unless carried out during the $\mathrm{NH}$ winter and spring or during the SH late spring and early summer. Sample time series of the various forcing terms for both hemispheres for specific months in winter and summer, shown in Fig. 8, further support this conclusion.

Figure 9 shows the annual cycle of the linear trends of the momentum tendency and its forcing terms over 1980-2001 in the polar regions for both ERA-40 and R-2 reanalysis. Overall, the trends in the EP flux divergence and in the momentum tendency agree well between the two independent reanalyses, as expected from the analysis of their time series. The largest trends in the EP flux divergence occur in the $\mathrm{SH}$ in November, when the trends are positive, and in December when the trends are negative. In November, the positive trends imply that the convergence of EP flux that is responsible for the breakdown of the polar vortex has weakened over the 1980-2001 period. In the ERA-40, the convergence of EP flux has decreased at a rate of $0.46 \mathrm{~m} \mathrm{~s}^{-1}$ day $^{-1}$ per decade, statistically significant at the $97.5 \%$ confidence level. Meanwhile, the convergence of EP flux has intensified in December at a rate of $0.38 \mathrm{~m} \mathrm{~s}^{-1}$ day $^{-1}$ per decade, statistically significant at the $99 \%$ level. This indicates a temporal shift in the strength of the planetary wave forcing from November to December in the SH polar region. These trends in the planetary wave activity are associated with statistically significant trends in the momentum tendency. Because the 22-yr mean momentum tendency is negative in November, the positive trend shown in Fig. 9 corresponds to a long-term weakening of the polar vortex deceleration and thus explains the persistence of the polar vortex into the summer that was discussed previously. In the $\mathrm{NH}$, the trends in the EP flux divergence are not significant like in the SH. Nonetheless, it is worthy to note that the EP flux divergence experiences a positive trend in both reanalyses in winter, although not statistically significant at the $95 \%$ confidence level. However, $\mathrm{Hu}$ and Tung (2003) find a statistically significant reduction in planetary wave activity in the $\mathrm{NH}$ high latitudes $\left(50^{\circ}-90^{\circ} \mathrm{N}\right)$ in late winter and early spring (JFM) in the NCEP reanalysis 
Table 1. 22-yr means and inter-dataset correlations of the momentum tendency and its forcing terms averaged between 100 and $20 \mathrm{hPa}$ and between $50^{\circ}-80^{\circ}$ for the ERA-40 and R-2 reanalyses. Means that are not statistically different from each other at the $95 \%$ level based on a two-tailed Student's $t$-test are bolded. Correlations that are statistically significant at the $95 \%$ level based on a one-tailed Student's $t$-test are bolded.

\begin{tabular}{|c|c|c|c|c|c|c|c|c|c|c|c|c|c|}
\hline & & Jan & Feb & Mar & Apr & May & Jun & Jul & Aug & Sep & Oct & Nov & Dec \\
\hline \multicolumn{14}{|c|}{ Northern Hemisphere } \\
\hline \multirow{3}{*}{$\begin{array}{l}\text { Momentum } \\
\text { tendency }\end{array}$} & ERA-40 mean & 0.01 & -0.12 & -0.22 & -0.27 & -0.10 & -0.03 & 0.06 & 0.12 & 0.17 & 0.18 & 0.04 & 0.12 \\
\hline & $\mathrm{R}-2$ mean & 0.00 & -0.12 & -0.22 & -0.27 & -0.09 & $-\mathbf{0 . 0 3}$ & 0.07 & 0.13 & 0.17 & 0.18 & 0.05 & 0.11 \\
\hline & Correlation & 1.00 & 1.00 & 1.00 & 1.00 & 1.00 & 0.98 & 0.99 & 0.99 & 0.99 & 1.00 & 1.00 & 0.99 \\
\hline \multirow{3}{*}{$\begin{array}{l}\text { Coriolis }+ \\
\text { advective } \\
\text { terms }\end{array}$} & ERA-40 mean & 1.59 & 1.6 & 1.36 & 1.05 & 0.41 & -0.01 & 0.03 & 0.40 & 0.82 & 1.07 & 1.68 & 1.46 \\
\hline & $\mathrm{R}-2$ mean & 1.31 & 1.36 & 1.37 & 1.13 & 0.56 & 0.45 & 0.67 & 1.03 & 1.39 & 1.53 & 1.66 & 1.34 \\
\hline & Correlation & 0.75 & 0.79 & 0.58 & 0.53 & 0.17 & -0.06 & -0.26 & -0.01 & -0.02 & 0.08 & 0.3 & 0.37 \\
\hline \multirow{3}{*}{$\begin{array}{l}\text { EP flux } \\
\text { divergence }\end{array}$} & ERA-40 mean & -1.27 & -1.45 & -1.54 & -1.28 & -0.59 & -0.36 & -0.34 & -0.43 & -0.72 & -0.89 & -1.26 & -0.94 \\
\hline & $\mathrm{R}-2$ mean & -1.19 & -1.36 & -1.45 & -1.19 & -0.56 & -0.34 & -0.35 & -0.46 & -0.77 & -0.99 & -1.32 & $-\mathbf{1 . 0 7}$ \\
\hline & Correlation & 0.92 & 0.97 & 0.94 & 0.98 & 0.99 & 0.64 & 0.63 & 0.84 & 0.87 & 0.75 & 0.76 & 0.81 \\
\hline \multirow{3}{*}{$\begin{array}{l}\text { Residual } \\
\text { term }\end{array}$} & ERA-40 mean & -0.31 & -0.26 & -0.04 & -0.04 & 0.09 & 0.34 & 0.38 & 0.16 & 0.07 & 0.00 & -0.38 & -0.40 \\
\hline & $\mathrm{R}-2$ mean & -0.12 & -0.12 & -0.14 & -0.20 & -0.09 & -0.13 & -0.26 & -0.44 & -0.45 & -0.35 & -0.29 & -0.16 \\
\hline & Correlation & 0.33 & 0.38 & -0.14 & 0.07 & -0.38 & 0.01 & -0.15 & -0.01 & -0.14 & -0.26 & -0.29 & -0.11 \\
\hline \multicolumn{14}{|c|}{ Southern Hemisphere } \\
\hline \multirow{3}{*}{$\begin{array}{l}\text { Momentum } \\
\text { tendency }\end{array}$} & ERA-40 mean & 0.06 & 0.21 & 0.21 & 0.30 & 0.20 & 0.15 & 0.12 & 0.07 & -0.04 & -0.28 & -0.63 & -0.33 \\
\hline & R-2 mean & 0.07 & 0.21 & 0.20 & 0.30 & 0.19 & 0.13 & 0.12 & 0.06 & -0.06 & $-\mathbf{0 . 3 0}$ & -0.60 & -0.30 \\
\hline & Correlation & 0.98 & 0.98 & 0.96 & 0.95 & 0.98 & 0.92 & 0.97 & 0.98 & 0.96 & 0.97 & 0.99 & 0.99 \\
\hline \multirow{3}{*}{$\begin{array}{l}\text { Coriolis }+ \\
\text { advective } \\
\text { terms }\end{array}$} & ERA-40 mean & 0.57 & 0.96 & 1.29 & 1.23 & 1.14 & 0.94 & 0.97 & 0.72 & 0.58 & 1.05 & 1.13 & 0.87 \\
\hline & $\mathrm{R}-2$ & 0.39 & 0.75 & 1.07 & 1.00 & 0.66 & 0.45 & 0.46 & 0.35 & 0.41 & 0.50 & 0.70 & 0.58 \\
\hline & Correlation & -0.24 & -0.27 & -0.09 & 0.37 & 0.36 & 0.25 & 0.17 & 0.29 & 0.18 & 0.35 & 0.66 & 0.6 \\
\hline \multirow{3}{*}{$\begin{array}{l}\text { EP flux } \\
\text { divergence }\end{array}$} & ERA-40 mean & -0.55 & -0.64 & -0.73 & -0.56 & -0.42 & -0.29 & -0.37 & -0.40 & -0.61 & -1.11 & -1.66 & -1.29 \\
\hline & R-2 mean & -0.35 & -0.45 & -0.70 & -0.62 & -0.45 & -0.40 & -0.41 & -0.36 & -0.52 & -0.88 & -1.28 & -0.89 \\
\hline & Correlation & 0.86 & 0.80 & 0.78 & 0.62 & 0.40 & 0.45 & 0.36 & 0.22 & 0.40 & 0.82 & 0.94 & 0.97 \\
\hline \multirow{3}{*}{$\begin{array}{l}\text { Residual } \\
\text { term }\end{array}$} & ERA-40 mean & 0.05 & -0.11 & -0.36 & -0.37 & -0.52 & -0.50 & -0.47 & -0.26 & -0.01 & -0.22 & -0.10 & 0.09 \\
\hline & R-2 mean & 0.03 & -0.09 & -0.17 & -0.08 & -0.02 & 0.08 & 0.08 & 0.07 & 0.05 & 0.09 & $-\mathbf{0 . 0 3}$ & 0.01 \\
\hline & Correlation & -0.24 & -0.50 & 0.02 & -0.25 & -0.25 & -0.30 & 0.21 & -0.28 & -0.28 & -0.03 & 0.08 & 0.13 \\
\hline
\end{tabular}

1. The lack of statistical significance in this study is possibly due to the large averaging area ( 100 to $20 \mathrm{hPa}$ and $50^{\circ}-80^{\circ}$ ) so that further analysis without the averaging is necessary to determine whether the trends in the planetary wave activity are real or not. Like in the SH, these trends in the EP flux divergence are associated with positive trends in the momentum tendency, and therefore can explain the positive trends in the zonal-mean zonal wind that occur in March (see Fig. 7).

The Coriolis and advective terms exhibit trends that are consistent between the two reanalyses in the $\mathrm{NH}$ winter and early spring and in the $\mathrm{SH}$ in November. During these months, the EP flux divergence experiences a weakening which results in a long-term decrease in the planetary wave activity driving the B-D circulation. This shows consistency between the long-term changes in planetary wave activity and in the B-D circulation, as expected from the wave-mean flow interaction theory. As is expected from the statistics of the time series presented in Table 1, there are large discrepancies in the sign of the trends between the ERA- 40 and R-2 reanalyses for the remaining months. In particular, the ERA-
40 Coriolis term displays a positive trend in the $\mathrm{NH}$ from April to November, implying an intensification of the B-D circulation. This is consistent with the response of the B-D circulation to a doubled $\mathrm{CO}_{2}$ climate found in several studies (Eichelberger and Hartmann, 2005; Butchart et al., 2006; Haklander et al., 2008). However, the trends in the Coriolis term are negative all year long in the R-2 reanalysis. As such, the trends in the B-D circulation present a very large uncertainty that largely stems from inconsistencies between reanalysis datasets (Iwasaki et al., 2009). A noticeable feature in this analysis is that the trends in the Coriolis term and in the residual term mirror each other well in both reanalyses, especially when the trends in the EP flux divergence are weak. Since it has been established that in models gravity wave drag plays a significant role in driving long-term changes in the B-D circulation (Li et al., 2008; McLandress and Shepherd, 2009; Butchart et al., 2010), it is expected that trends in the Coriolis and residual terms would mirror each other to some degree. Finally, it should be noted that in the R2 reanalysis, a large trend in the residual term occurs in the 
a) NORTHERN HEMISPHERE
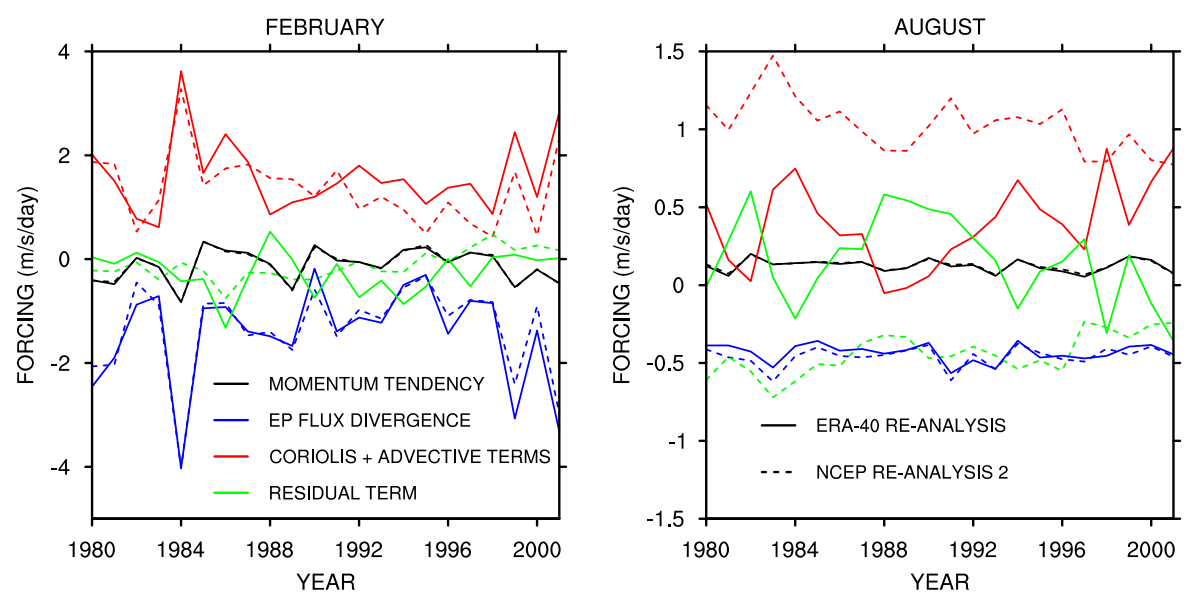

b) SOUTHERN HEMISPHERE
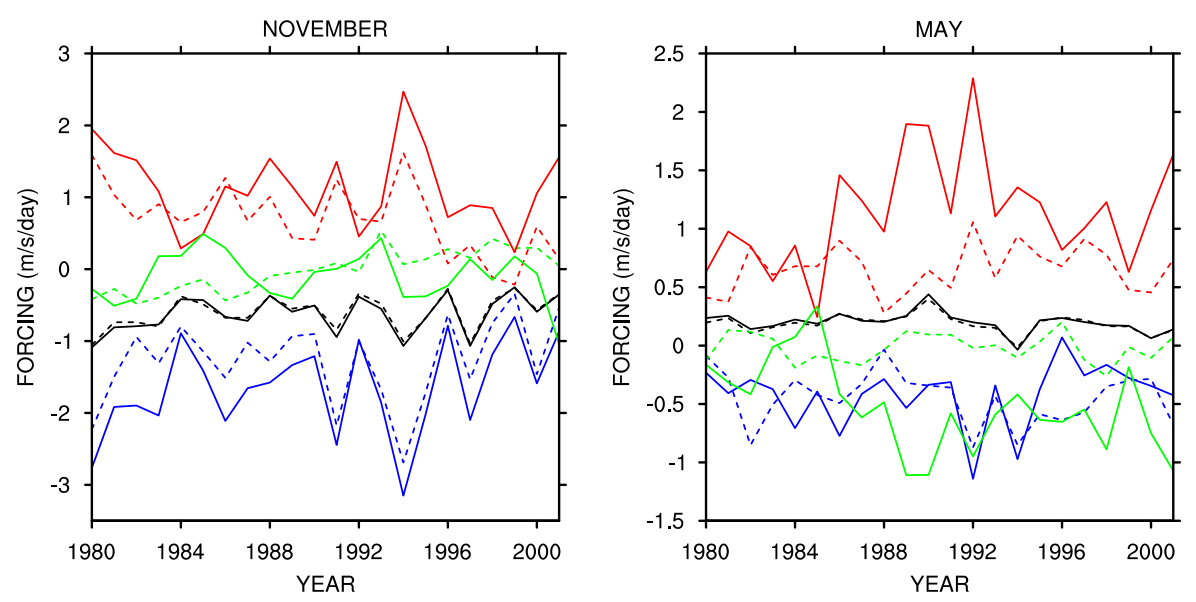

Fig. 8. Times series of the momentum tendency and its forcing terms averaged between 100 and $20 \mathrm{hPa}$ and between $50^{\circ}-80^{\circ}$ for the ERA-40 (solid lines) and R-2 (dashed lines) reanalyses.

SH in November concurrently to the decrease in planetary wave activity. This would suggest that long-term changes in unresolved wave activity, mainly gravity wave drag, could play a significant role in the delay of the polar vortex in the SH late spring. However, this is not supported by the ERA40 reanalysis.

Overall, Fig. 9 underlines the significant role of the planetary wave activity in driving long-term changes in the zonalmean zonal wind. This analysis shows that trends in polar vortex are preceded by trends in the momentum tendency and in the planetary wave forcing, with a lag of one month. This is particularly obvious in November and December in the $\mathrm{SH}$, suggesting that long-term weakening in planetary wave activity plays a significant role in delaying the breakdown of the polar vortex in the SH late spring. Also, a weakening of the B-D circulation is identified in both reanalyses concurrently to the long-term weakening in planetary wave activity in the $\mathrm{NH}$ winter and the SH late spring. During the rest of the year, this analysis suggests that long-term changes in the B-D circulation are very uncertain because of the lack of agreement in the signs of the trends between the ERA- 40 and $\mathrm{R}-2$ reanalyses.

The vertical structure of the trends in the ERA-40 EP flux vector and its divergence in the SH for the month of November is shown in Fig. 10. It indicates a strong and significant decrease in the convergence of EP flux in the polar region between 100 and $10 \mathrm{~Pa}$, statistically significant at the $95 \%$ confidence level. The decrease in planetary wave activity is mainly associated with stationary waves, though the statistical significance of the trends in the stationary EP flux divergence is weak. Figure 10 also shows that there is no significant trend associated with transient wave activity. The analysis of the trends in the EP flux vector demonstrates that significantly less energy is being transported vertically into the stratospheric polar region by planetary waves, especially by stationary waves. Meanwhile, trends in the horizontal component of the EP flux are weak and not significant. A similar analysis is done for the month of February in the $\mathrm{NH}$ 
a) ERA-40 RE-ANALYSIS
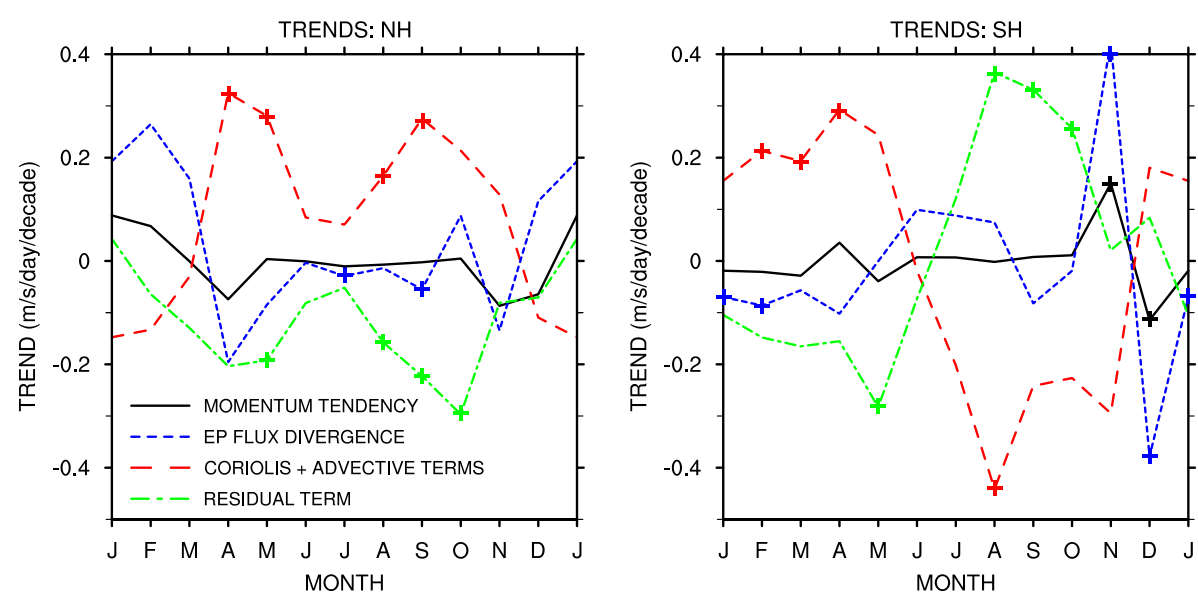

b) NCEP RE-ANALYSIS 2
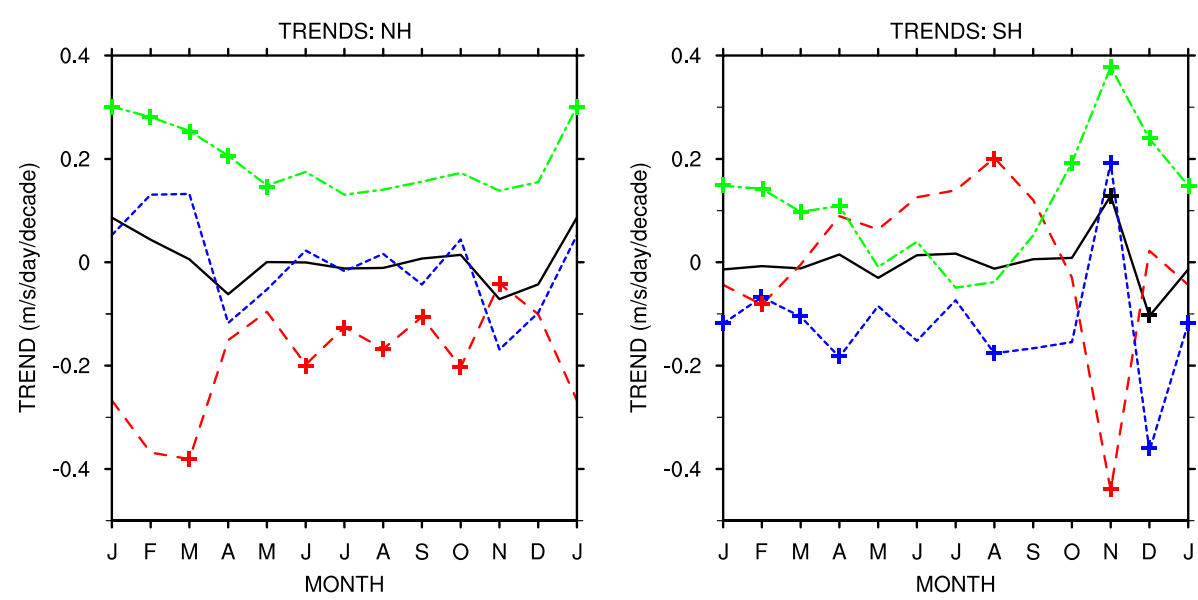

Fig. 9. Annual cycle of the trends in the momentum tendency and its forcing terms for the ERA-40 and R-2 reanalyses. The trends are calculated after the momentum tendency and its forcing terms are averaged between 100 and $20 \mathrm{hPa}$ and between $50^{\circ}-80^{\circ}$. Trends that are statistically significant at the $95 \%$ level are indicated with a cross.

and shown in Fig. 11 for the ERA-40 reanalysis. A significant decrease in the strength of the EP flux divergence is present in the subpolar and polar region below $100 \mathrm{hPa}$ and above $20 \mathrm{hPa}$ with competing contributions from stationary (intensification) and transient (weakening) waves. Overall, the trend analysis of the EP flux divergence is noisy and does not paint a clear picture. However, the trends in the EP flux vector exhibit more distinct patterns. Transient waves transport significantly less energy into the stratosphere in the later years of this study, while stationary waves have a significant tendency toward more poleward refraction in the polar region. While a positive trend in the vertical component of the stationary EP flux vector is present between $50^{\circ}-60^{\circ}$, consistent with the findings of Kanukhina et al. (2008), this trend is not statistically significant. The study of the trends in the NH EP flux forcing for the month of November (not shown) reveals an increase in wave activity, which is statistically significant at midlatitudes and at several pressure levels in the polar region. This increase is principally due to transient waves propagating significantly more from the troposphere into the stratosphere in the later years. Concurrently, the equatorward refraction of planetary waves is greatly increased.

The planetary wave forcing in the R-2 reanalysis is in very good agreement with that of the ERA-40 reanalysis indicating confidence in the long term changes. In particular, the analysis of the R-2 planetary wave trends for the month of February in the NH (see Fig. 12) confirms the presence of significant trends in the propagation of wave energy by planetary and transient waves, but without significant trends in the total EP flux divergence. As such, these results suggest that investigating trends in planetary wave activity based on flux terms calculated using monthly data (i.e. considering only stationary processes) does not provide the full picture since the contribution from transient processes is considerable. Indeed, if trends in the stationary wave activity alone 

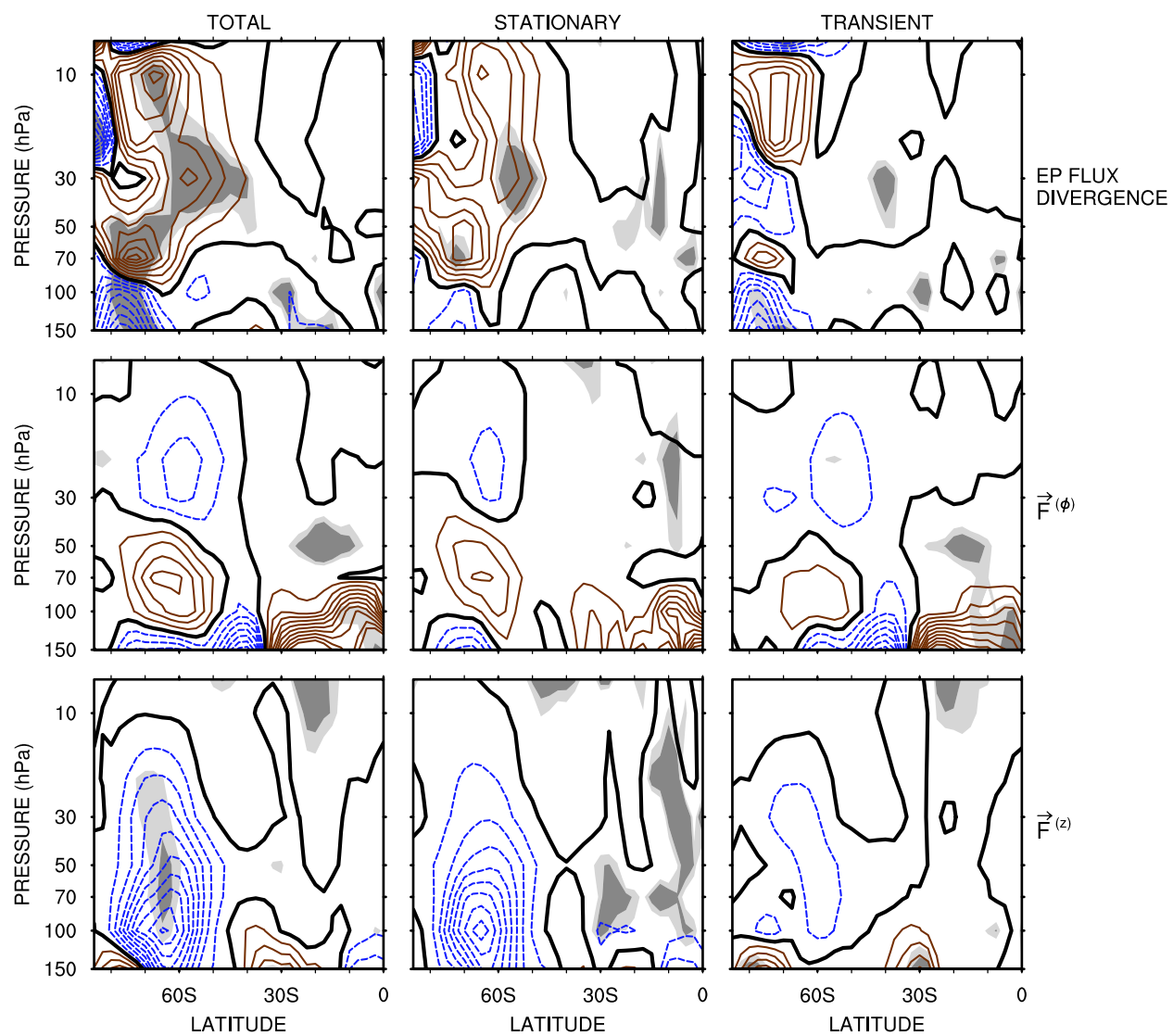

Fig. 10. Trends in the ERA-40 EP flux vector and its divergence, including stationary and transient components, for the month of November in the SH. Dashed blue (solid brown) lines represent negative (positive) trends while the bold solid line represent the zero-line. Light grey (dark grey) shadings represent the $90 \%(95 \%)$ statistical significance level of the trends. Contour interval is $0.2 \mathrm{~m} \mathrm{~s}^{-1} \mathrm{day}^{-1}$ per decade for the EP flux divergence, $2 \times 10^{5} \mathrm{~kg} \mathrm{~s}^{-2}$ per decade for $\boldsymbol{F}^{(\phi)}$ and $2 \times 10^{3} \mathrm{~kg} \mathrm{~s}^{-2}$ per decade for $\boldsymbol{F}^{(z)}$.

were investigated for the month of February in the $\mathrm{NH}$, one could easily misinterpret the results. For this reason, we suggest that trend analysis of planetary waves systematically include an analysis of both stationary and transient components of the EP flux vector and of its divergence.

In general, long-term changes in the planetary wave activity in the $\mathrm{NH}$ polar region are associated with transient waves, a finding in agreement with McLandress and Shepherd (2009). Meanwhile, the trends in the EP flux in the SH are largely due to changes in stationary waves. Besides, the systematic analysis of trends in the EP flux vector and its divergence reveals long-term changes consistent with that of the polar vortex. In the $\mathrm{SH}$, a significant decrease in the planetary wave activity occurs in November, one month before the strongest and most significant positive trend in the zonal-mean zonal wind that corresponds to a delay in the breakdown of the polar vortex.

\section{Conclusions}

An analysis of the budget of the TEM momentum equation in the ERA-40 and R-2 reanalyses provides further insight into the role of planetary waves and unresolved processes, deduced to be gravity waves, on the stratospheric zonal-mean flow. The resolved terms in the momentum equation are the zonal momentum tendency, the Coriolis force and advective terms due to the B-D circulation, and the Eliassen-Palm flux divergence, which is a measure of the planetary wave forcing. In addition, a residual term is calculated from the other terms in the TEM momentum equation. The climatology of the resolved forcing terms is consistent with the wave-mean flow interaction theory, as the EP flux divergence contributes to the breakdown of the polar vortex while being balanced by the Coriolis force due to the B-D circulation. Meanwhile, the residual term displays many of the characteristic features of a gravity wave drag, including location, seasonality and magnitude compared to model simulations and measurements (Palmer et al., 1986; Dunkerton, 1997; Scinocca and McFarlane, 2000; McFarlane, 2000; Scaife et al., 2002; Fritts and 

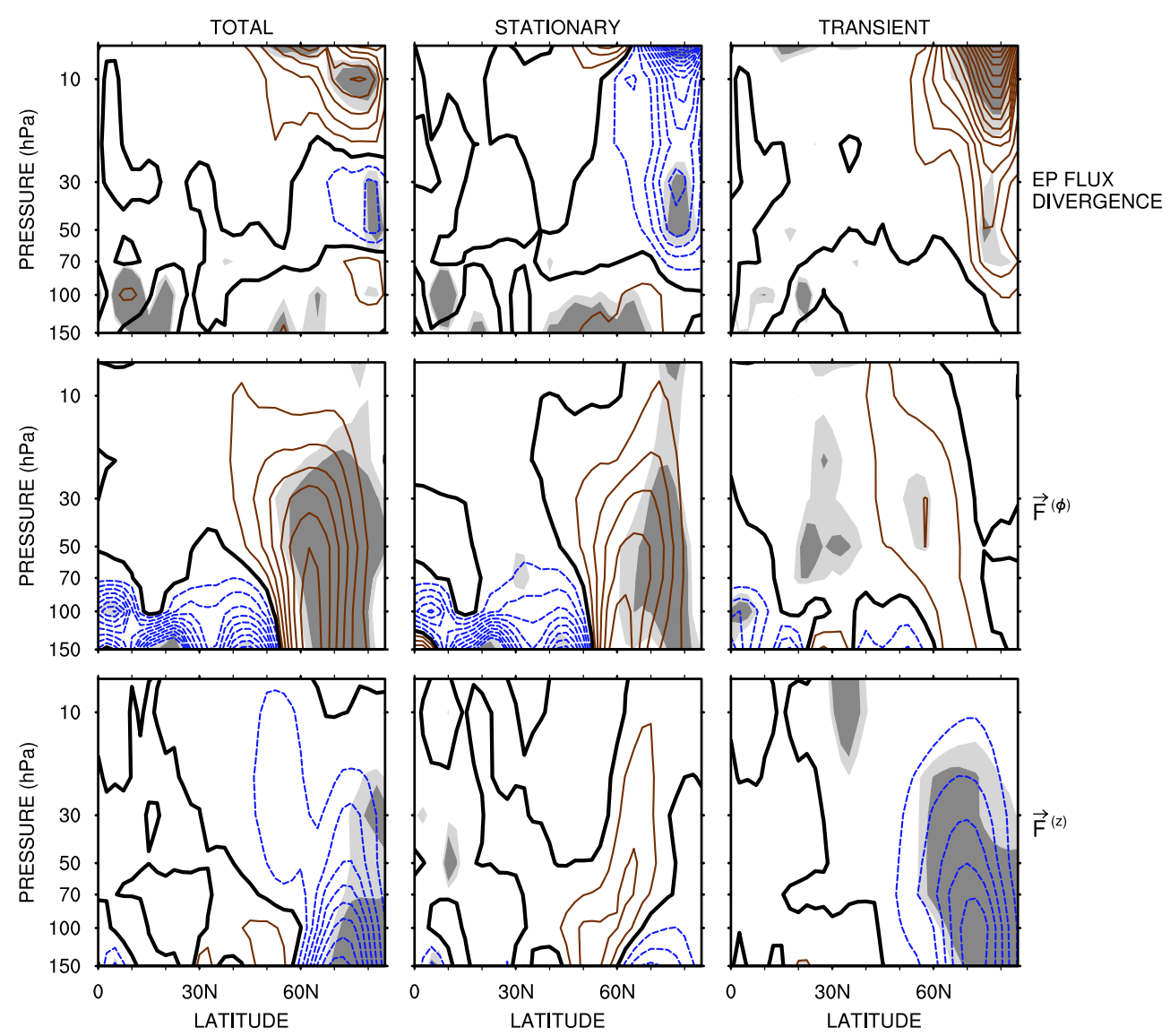

Fig. 11. Same as Fig. 10 but for the month of February in the NH. Contour interval is $0.5 \mathrm{~m} \mathrm{~s}^{-1}$ day $^{-1}$ per decade for the EP flux divergence, $5 \times 10^{5} \mathrm{~kg} \mathrm{~s}^{-2}$ per decade for $\boldsymbol{F}^{(\phi)}$ and $5 \times 10^{3} \mathrm{~kg} \mathrm{~s}^{-2}$ per decade for $\boldsymbol{F}^{(z)}$.

Alexander, 2003) and was identified as a gravity wave drag in numerous studies (Hartmann, 1976; Hamilton, 1983; Smith and Lyjak, 1985; Alexander and Rosenlof, 1996, 2003). As a result, the momentum budget based on the TEM framework presented in this study provides a reasonable method to investigate the dynamical forcing in the stratosphere over the whole globe and over long time periods using reanalysis datasets. The momentum budget outlines the significant contribution of the residual term in driving the stratospheric circulation, as it exhibits magnitudes similar to that of the EP flux divergence in some regions of the stratosphere. In fact, unresolved waves, identified as gravity waves, may play an equally large role as planetary waves in driving the B-D circulation, especially when the EP flux divergence is weak. The correlation analyses in Fig. 6 further highlight the differences between the balances in the momentum budget in the troposphere and stratosphere.

The trend analysis shows that there is a statistically significant weakening of the Northern Hemisphere stratospheric polar night jet in December and a moderately significant strengthening in March, hinting at a delay of the breakdown of the polar vortex. Both changes in the strength of the westerly winds follow changes in the planetary wave ac- tivity, mainly due to transient waves, with a delay of one month. This is consistent with the findings of Karpetchko and Nikulin (2004) who observed a decrease in the stratospheric eddy heat flux in January and February in the NCEP reanalysis 1. In their study, Karpetchko and Nikulin (2004) fail to link the trend in the planetary wave activity to changes in the zonal-mean zonal wind because they only investigate trends in the polar night jet at the same period, and not a month later. This underlines the importance of a complete analysis of the seasonality of the long-term changes in the stratospheric dynamics. In the Southern Hemisphere, the polar vortex also shows a tendency to persist further into the SH summertime. Like in the $\mathrm{NH}$, the trend in the $\mathrm{SH}$ polar vortex follows a statistically significant decrease in the intensity of the stationary EP flux divergence, also with a delay of one month. However, the two hemispheres differ in the source of the decrease in wave activity: transient waves in the $\mathrm{NH}$ and stationary waves in the SH.

Several studies have attributed the ultimate cause of the delay in the breakdown of the SH polar vortex to ozone depletion (Thompson and Solomon, 2002; Renwick, 2004). Weare (2009) showed that there is a distinct symmetric mode between the zonal wind and ozone in the $\mathrm{SH}$ and that this 

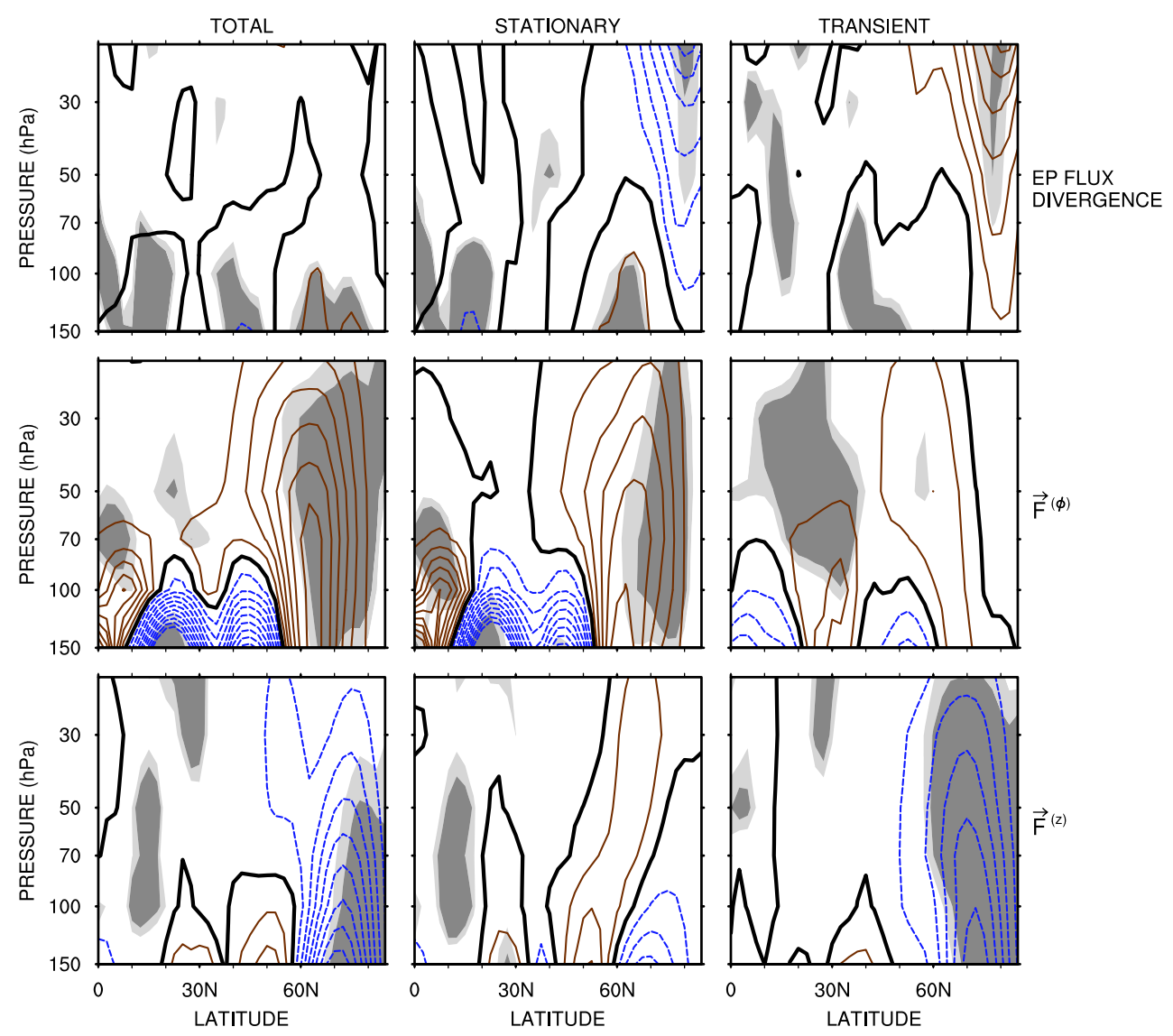

Fig. 12. Same as Fig. 11 but for the R-2 reanalysis.

mode contains a clear long-term trend. Hu and Tung (2003) advance a mechanism whereby ozone depletion leads to an enhanced meridional temperature gradient near the subpolar stratosphere, strengthening westerly winds. The strengthened winds would then refract planetary waves toward low latitudes and cause the reduction in wave activity in high latitudes. It is also possible that the ozone depletion directly impacts the vertical propagation of planetary waves and in turn the zonal wind, as suggested by the ozone-modified refractive index for vertically propagating planetary waves introduced by Nathan and Cordero (2007), which accounts for how ozone photochemistry, ozone transport, and Newtonian cooling can combine to modify wave propagation and drag on the zonal-mean flow. There is no doubt that ozone changes result in changes in the strength of the zonal wind, especially in the SH where ozone depletion is very large. However, the strongest ozone trends over Antarctica take place from September to November in the ERA-40 (Monier and Weare, 2011), while the statistically significant longterm changes in the zonal wind are limited to the months of December and January. This indicates a delay of two months in the dynamical response to ozone depletion in the SH. This analysis suggests that the absence of any significant trends in the zonal wind in September and October is due to the absence of strong planetary wave activity during these months (see Fig. 1). On the other hand the planetary wave activity is at its peak in November, which leads to the breakdown of the polar vortex. The strong planetary wave activity can be modulated by the strength of the westerlies (itself impacted by ozone depletion) and can provide a strong positive feedback to the strength of the zonal-mean zonal wind. This would explain why the long-term changes in the polar vortex occur several months following the ozone depletion, and one month following a significant decrease in the planetary wave forcing. Furthermore, the significant increase in planetary wave activity in the SH in December is most likely related to the delayed breakup of the polar vortex: as the transition to easterlies in the stratosphere occurs later in the season, the stratosphere can still support wave propagation, resulting in an increased propagation in December. In the $\mathrm{NH}$, the planetary wave forcing is sustained from fall until late spring, and the timing of the strongest ozone depletion coincides with the break down of the polar vortex, in March (Monier and Weare, 2011). As a result, there is no delay between the ozone trends and the response of the zonal winds. As such, this analysis underlines the important role of planetary wave feedback in 
the dynamical response of the stratosphere to ozone changes. This study also suggests that the long-term decrease in planetary wave activity leading to a sustained polar vortex is primarily due to a reduction in the vertical propagation of planetary waves. Indeed, the changes in the meridional propagation of planetary waves are not statistically significant in the SH while they lead to more refraction toward the pole in the $\mathrm{NH}$. These results are supported by both ERA- 40 and R- 2 reanalyses which show very good agreement in the long-term changes in planetary wave activity.

Finally, a weakening of the B-D circulation is identified in both reanalyses in the $\mathrm{NH}$ winter and the SH late spring. This is due to the weakening in planetary wave activity discussed previously. During the remaining months of the year this analysis suggests that long-term changes in the B-D circulation are very uncertain because of the lack of agreement in the signs of the trends between the ERA-40 and $\mathrm{R}-2$ reanalyses. This lack of complete agreement between the two reanalyses is not surprising since there exists considerable discrepancy in the representation of the B-D circulation among the various reanalyses currently available (Randel et al., 2008; Iwasaki et al., 2009). Some of the biases can arise from new instruments becoming available and assimilation techniques (Thorne, 2008; Screen and Simmonds, 2011). A noticeable feature is that the trends in the Coriolis term and in the residual term mirror each other well in both reanalyses, especially when the trends in the EP flux divergence are weak. This could suggest that the long-term changes in the B-D circulation are largely associated with long-term changes in unresolved processes. This finding is consistent with the fact that gravity wave driving is believed to dominate outside of the wintertime in the stratosphere, when the EP flux divergence is small (Fritts and Alexander, 2003). This is also on par with the findings of Li et al. (2008), McLandress and Shepherd (2009) and Butchart et al. (2010) who show that gravity wave drag plays a considerable role in driving long-term changes in the B-D circulation in models. For example, McLandress and Shepherd (2009) find that parameterized orographic gravity wave drag account for $40 \%$ of the long-term trend in annual mean net upward mass flux at $70 \mathrm{hPa}$.

Although many studies rely on planetary waves to explain stratospheric dynamics, this budget analysis draws attention to the need to account for gravity waves. As a result, an emphasis should be put on developing models with capabilities to accurately simulate gravity waves, both orographic and convectively forced. Furthermore, there is a clear need for a global dataset of gravity wave drag in the stratosphere for comparison purposes. Thus, this study should be expanded using other reanalysis datasets and various atmospheric models. The various reanalysis datasets will undoubtedly have different errors and biases compared to more fundamental observations. The sources of biases in the various reanalysis datasets can include: differences in the data sources and their treatment and processing (e.g., satellite radiance measure- ments are directly used in the ERA-40 reanalysis while temperature retrievals are used in the R-2 reanalysis); differences in the assimilation techniques (e.g., 3-D variational assimilation in the ERA-40 reanalysis but 4-D variational assimilation in the ERA-Interim); differences in the model parameterization suites (e.g. representation of gravity wave drag, momentum transport...). Unfortunately, it can be very difficult to isolate the contributions from these potential sources and more work is necessary in order to understand their impacts. In particular, this study shows that two independent reanalysis datasets can show trends in the Brewer-Dobson circulation with opposite signs. This suggests that analyzing trends based on a single reanalysis dataset can be particularly misleading. There are many more issues that need to be addressed regarding long-term changes in the stratospheric dynamics. Since ozone depletion can directly alter planetary wave activity in the stratosphere through ozone photochemistry, ozone transport, and Newtonian cooling, there is a need for more theoretical and applied studies to investigate these mechanisms. Similarly, the impact of climate change due to increasing anthropogenic emissions of greenhouse gas on the wave activity in the stratosphere needs to be better resolved.

\section{Supplementary material related to this article is available online at: http://www.atmos-chem-phys.net/11/12751/2011/ acp-11-12751-2011-supplement.pdf.}

Acknowledgements. The authors want to thank Terrence R. Nathan and R. Alan Plumb and the various anonymous reviewers for their comments. ERA-40 data were provided by the European Centre for Medium-Range Weather Forecasts from their website at http://data-portal.ecmwf.int/data/d/era40_daily/. NCEP Reanalysis 2 data were provided by the NOAA/OAR/ESRL PSD, Boulder, Colorado, USA, from their website at http://www.esrl.noaa.gov/psd/. This study was partially supported by the National Science Foundation grant ATM0733698.

Edited by: P. Haynes

\section{References}

Alexander, M. J. and Rosenlof, K. H.: Nonstationary gravity wave forcing of the stratospheric zonal mean wind, J. Geophys. Res., 101, 23465-23474, 1996.

Alexander, M. J. and Rosenlof, K. H.: Gravity-wave forcing in the stratosphere: Observational constraints from the Upper Atmosphere Research Satellite and implications for parameterization in global models, J. Geophys. Res., 108, 4597, doi:10.1029/2003JD003373, 2003.

Alexander, M. J., Geller, M., McLandress, C., Polavarapu, S., Preusse, P., Sassi, F., Sato, K., Eckermann, S., Ern, M., Hertzog, A., Kawatani, Y., Pulido, M., Shaw, T. A., Sigmond, M., Vincent, R., and Watanabe, S.: Recent developments in gravity-wave effects in climate models and the global distribution of gravity-wave momentum flux from observations 
and models, Quart. J. Roy. Meteor. Soc., 136, 1103-1124, doi:10.1002/qj.637, 2010.

Andrews, D. G., Mahlman, J. D., and Sinclair, R. W.: Eliassen-Palm Diagnostics of Wave-Mean Flow Interaction in the GFDL "SKYHI" General Circulation Model, J. Atmos. Sci., 40, 2768-2784, doi:10.1175/15200469(1983)040<2768:ETWATM > 2.0.CO;2, 1983.

Andrews, D. G., Holton, J. R., and Leovy, C. B.: Middle Atmosphere Dynamics, Academic Press, 1987.

Baldwin, M. P. and Dunkerton, T. J.: Propagation of the Arctic Oscillation from the stratosphere to the troposphere, J. Geophys. Res., 104, 30937-30946, doi:10.1029/1999JD900445, 1999.

Baldwin, M. P. and Dunkerton, T. J.: Stratospheric Harbingers of Anomalous Weather Regimes, Science, 294, 581-584, doi:10.1126/science.1063315, 2001.

Baldwin, M. P., Gray, L. J., Dunkerton, T. J., Hamilton, K., Haynes, P. H., Randel, W. J., Holton, J. R., Alexander, M. J., Hirota, I., Horinouchi, T., Jones, D. B. A., Kinnersley, J. S., Marquardt, C., Sato, K., and Takahashi, M.: The Quasi-Biennial Oscillation, Rev. Geophys., 39, 179-229, doi:10.1029/1999RG000073, 2001.

Baldwin, M. P., Dameris, M., and Shepherd, T. G.: How will the stratosphere affect climate change?, Science, 316, 1576-1577, doi:10.1126/science.1144303, 2007.

Black, R. X.: Stratospheric Forcing of Surface Climate in the Arctic Oscillation, J. Climate, 15, 268-277, doi:10.1175/15200442(2002)015<0268:SFOSCI > 2.0.CO;2, 2002.

Butchart, N., Scaife, A. A., Bourqui, M., de Grandpre, J., Hare, S. H. E., Kettleborough, J., Langematz, U., Manzini, E., Sassi, F., Shibata, K., Shindell, D., and Sigmond, M.: Simulations of anthropogenic change in the strength of the Brewer-Dobson circulation, Clim. Dynam., 27, 727-741, doi:10.1007/s00382-0060162-4, 2006.

Butchart, N., Cionni, I., Eyring, V., Shepherd, T. G., Waugh, D. W., Akiyoshi, H., Austin, J., Bruehl, C., Chipperfield, M. P., Cordero, E., Dameris, M., Deckert, R., Dhomse, S., Frith, S. M., Garcia, R. R., Gettelman, A., Giorgetta, M. A., Kinnison, D. E., Li, F., Mancini, E., McLandress, C., Pawson, S., Pitari, G., Plummer, D. A., Rozanov, E., Sassi, F., Scinocca, J. F., Shibata, K., Steil, B., and Tian, W.: Chemistry-Climate Model Simulations of Twenty-First Century Stratospheric Climate and Circulation Changes, J. Climate, 23, 5349-5374, doi:10.1175/2010JCLI3404.1, 2010.

Callaghan, P. F. and Salby, M. L.: Three-Dimensionality and Forcing of the Brewer-Dobson Circulation, J. Atmos. Sci., 59, 976-991, doi:10.1175/15200469(2002)059<0976:TDAFOT>2.0.CO;2, 2002.

Charney, J. G. and Drazin, P. G.: Propagation of Planetary-Scale Disturbances from the Lower into the Upper Atmosphere, J. Geophys. Res., 66, 83-109, doi:10.1029/JZ066i001p00083, 1961.

Charney, J. G. and Eliassen, A.: A numerical method for predicting the perturbations of the middle latitude westerlies, Tellus, 1, 3854, doi:10.1111/j.2153-3490.1949.tb01258.x, 1949.

Chun, H. Y., Song, I. S., Baik, J. J., and Kim, Y. J.: Impact of a Convectively Forced Gravity Wave Drag Parameterization in NCAR CCM3, J. Climate, 17, 3530-3547, doi:10.1175/15200442(2004)017<3530:IOACFG>2.0.CO;2, 2004.

Dunkerton, T.: On the Mean Meridional Mass Motions of the Stratosphere and Mesosphere, J. At- mos. Sci., 35, 2325-2333, doi:10.1175/15200469(1978)035<2325:OTMMMM>2.0.CO;2, 1978.

Dunkerton, T. J.: Annual variation of deseasonalized mean flow acceleration in the equatorial lower stratosphere, J. Meteor. Soc. Japan, 68, 499-508, 1990.

Dunkerton, T. J.: The role of gravity waves in the quasi-biennial oscillation, J. Geophys. Res., 102, 26053-26076, 1997.

Edmon Jr, H. J., Hoskins, B. J., and McIntyre, M. E.: Eliassen-Palm Cross Sections for the Troposphere, J. Atmos. Sci., 37, 2600-2616, doi:10.1175/15200469(1980)037<2600:EPCSFT>2.0.CO;2, 1980.

Eichelberger, S. J. and Hartmann, D. L.: Changes in the strength of the Brewer-Dobson circulation in a simple AGCM, Geophys. Res. Lett., 32, L15807, doi:10.1029/2005GL022924, 2005.

Fritts, D. C. and Alexander, M. J.: Gravity wave dynamics and effects in the middle atmosphere, Rev. Geophys., 41, 1003, doi:10.1029/2001RG000106, 2003.

Haklander, A. J., Siegmund, P. C., Sigmond, M., and Kelder, H. M.: How does the northern-winter wave driving of the Brewer-Dobson circulation increase in an enhancedCO2 climate simulation?, Geophys. Res. Lett., 35, L07702, doi:10.1029/2007GL033054, 2008.

Hamilton, K.: Diagnostic Study of the Momentum Balance in the Northern Hemisphere Winter Stratosphere, Mon. Wea. Rev., 111, 1434-1441, 1983.

Hartley, D. E., Villarin, J. T., Black, R. X., and Davis, C. A.: A new perspective on the dynamical link between the stratosphere and troposphere, Nature, 391, 471-474, doi:10.1038/35112, 1998.

Hartmann, D. L.: The Dynamical Climatology of the Stratosphere in the Southern Hemisphere during Late Winter 1973, J. Atmos. Sci., 33, 1789-1802, 1976.

Haynes, P.: Stratospheric Dynamics, Annu. Rev. Fluid Mech., 37, 263-293, doi:10.1146/annurev.fluid.37.061903.175710, 2005.

Haynes, P. H., Marks, C. J., McIntyre, M. E., Shepherd, T. G., and shine, K. P.: On the "Downward Control" of Extratropical Diabatic Circulations by Eddy-Induced Mean Zonal Forces, J. Atmos. Sci., 48, 651-679, 1991.

Helfand, H. M., C., J. J., Pfaendtner, J., Tenenbaum, J., and Kalnay, E.: The Effect of a Gravity Wave Drag Parameterization Scheme on the GLA Fourth Order General Circulation Model Forecasts, in: Short- and Medium-Range Numerical Weather Prediction: Collection of Papers Presented at the WMO/IUGG NWP Symposium, Tokyo, 4-8 August 1986, edited by: Matsuno, T., 729742, Meteorol. Soc. Japan, 1987.

Holton, J. R. and Wehrbein, W. M.: The Role of Forced Planetary Waves in the Annual Cycle of the Zonal Mean Circulation of the Middle Atmosphere, J. Atmos. Sci., 37, 1968-1983, doi:10.1175/1520-0469(1980)037<1968:TROFPW > 2.0.CO;2, 1980.

Hu, Y. and Tung, K. K.: Possible ozone-induced longterm changes in planetary wave activity in late winter, J. Climate, 16, 3027-3038, doi:10.1175/15200442(2003)016<3027:POLCIP>2.0.CO;2, 2003.

Ineson, S. and Scaife, A. A.: The role of the stratosphere in the European climate response to El Nino, Nat. Geosci., 2, 32-36, doi:10.1038/ngeo381, 2009.

Iwasaki, T., Hamada, H., and Miyazaki, K.: Comparisons of Brewer-Dobson Circulations Diagnosed from Reanalyses, J. Meteor. Soc. Japan, 87, 997-1006, doi:10.2151/jmsj.87.997, 2009. 
Kanamitsu, M.: Description of the NMC global data assimilation and forecast system, Wea. Forecasting, 4, 335-342, doi:10.1175/1520-0434(1989)004<0335:DOTNGD>2.0.CO;2, 1989.

Kanamitsu, M., Ebisuzaki, W., Woollen, J., Yang, S. K., Hnilo, J. J., Fiorino, M., and Potter, G. L.: NCEP-DOE AMIP-II reanalysis (R-2), Bull. Amer. Meteor. Soc., 83, 1631-1643, doi:10.1175/BAMS-83-11-1631, 2002.

Kanukhina, A. Y., Suvorova, E. V., Nechaeva, L. A., Skrygina, E. K., and Pogoreltsev, A. I.: Climatic variability of the mean flow and stationary planetary waves in the NCEP/NCAR reanalysis data, Ann. Geophys., 26, 1233-1241, doi:10.5194/angeo26-1233-2008, 2008.

Karpetchko, A. and Nikulin, G.: Influence of early winter upward wave activity flux on midwinter circulation in the stratosphere and troposphere, J. Climate, 17, 4443-4452, doi:10.1175/JCLI3229.1, 2004.

Karpetchko, A., Kyrö, E., and Knudsen, B. M.: Arctic and Antarctic polar vortices 1957-2002 as seen from the ERA-40 reanalyses, J. Geophys. Res., 110, D21109, doi:10.1029/2005JD006113, 2005.

Knudsen, B. M., Harris, N. R. P., Andersen, S. B., Christiansen, B., Larsen, N., Rex, M., and Naujokat, B.: Extrapolating future Arctic ozone losses, Atmos. Chem. Phys., 4, 1849-1856, doi:10.5194/acp-4-1849-2004, 2004.

Kuroda, Y.: Role of the stratosphere on the predictability of medium-range weather forecast: A case study of winter 2003-2004, Geophys. Res. Lett., 35, L19701, doi:10.1029/2008GL034902, 2008.

Kuroda, Y. and Kodera, K.: Role of planetary waves in the stratosphere-troposphere coupled variability in the northern hemisphere winter, Geophys. Res. Lett., 26, 2375-2378, doi:10.1029/1999GL900507, 1999.

Kuroda, Y. and Kodera, K.: Role of the Polar-night Jet Oscillation on the formation of the Arctic Oscillation in the Northern Hemisphere winter, J. Geophys. Res., 109, D11112, doi:10.1029/2003JD004123, 2004.

Lachlan-Cope, T. A., Connolley, W. M., and Turner, J.: The Role of the Non-Axisymmetric Antarctic Orography in forcing the Observed Pattern of Variability of the Antarctic Climate, Geophys. Res. Lett., 28, 4111-4114, doi:10.1029/2001GL013465, 2001.

Li, F., Austin, J., and Wilson, J.: The strength of the Brewer-Dobson circulation in a changing climate: Coupled chemistry-climate model simulations, J. Climate, 21, 40-57, doi:10.1175/2007JCLI1663.1, 2008.

Limpasuvan, V., Hartmann, D. L., Thompson, D. W. J., Jeev, K., and Yung, Y. L.: Stratosphere-troposphere evolution during polar vortex intensification, J. Geophys. Res., 110, D24101, doi:10.1029/2005JD006302, 2005.

Lott, F. and Miller, M. J.: A new subgrid-scale orographic drag parametrization: Its formulation and testing, Quart. J. Roy. Meteor. Soc., 123, 101-127, doi:10.1002/qj.49712353704, 1997.

Madden, R. A. and Labitzke, K.: A free Rossby wave in the troposphere and stratosphere during January 1979, J. Geophys. Res., 86, 1247-1254, doi:10.1029/JC086iC02p01247, 1981.

McFarlane, N. A.: Gravity-Wave Drag, 297-320, Kluwer Academic Publishers, 2000.

McLandress, C.: On the importance of gravity waves in the middle atmosphere and their parameterization in general circulation models, J. Atmos. Sol.-Terr. Phys., 60, 1357-1383, 1998.
McLandress, C. and Shepherd, T. G.: Simulated Anthropogenic Changes in the Brewer-Dobson Circulation, Including Its Extension to High Latitudes, J. Climate, 22, 1516-1540, doi:10.1175/2008JCLI2679.1, 2009.

McWilliams, J. C.: Fundamentals of Geophysical Fluid Dynamics, Cambridge University Press, 2006.

Mieth, P., Grenfell, J. L., Langematz, U., and Kunze, M.: Sensitivity of the Freie Universitat Berlin Climate Middle Atmosphere Model (FUB-CMAM) to different gravity-wave drag parameterisations, Ann. Geophys., 22, 2693-2713, 2004.

Miyazaki, K. and Iwasaki, T.: Diagnosis of meridional ozone transport based on mass-weighted isentropic zonal means, J. Atmos. Sci., 62, 1192-1208, doi:10.1175/JAS3394.1, 2005.

Monier, E. and Weare, B. C.: Climatology and trends in the forcing of the stratospheric ozone transport, Atmos. Chem. Phys., 11, 6311-6323, doi:10.5194/acp-11-6311-2011, 2011.

Nathan, T. R. and Cordero, E. C.: An ozone-modified refractive index for vertically propagating planetary waves, J. Geophys. Res. 112, D02105, doi:10.1029/2006JD007357, 2007.

Nikulin, G. and Karpechko, A.: The mean meridional circulation and midlatitude ozone buildup, Atmos. Chem. Phys., 5, 31593172, doi:10.5194/acp-5-3159-2005, 2005.

Oort, A. H.: Global atmospheric circulation statistics, 1958-1973, Professional Paper 14, National Oceanic and Atmospheric Administration, Washington, D.C., 1983.

Palmer, T. N., Shutts, G. J., and Swinbank, R.: Alleviation of a systematic westerly bias in general circulation and numerical weather prediction models through an orographic gravity wave drag parametrization, Quart. J. Roy. Meteor. Soc., 112, 10011039, doi:10.1002/qj.49711247406, 1986.

Parish, T. R., Bromwich, D. H., and Tzeng, R. Y.: On the role of the Antarctic continent in forcing large-scale circulations in the high southern latitudes, J. Atmos. Sci., 51, 3566-3579, doi:10.1175/1520-0469(1994)051<3566:OTROTA > 2.0.CO;2, 1994.

Pascoe, C. L., Gray, L. J., Crooks, S. A., Juckes, M. N., and Baldwin, M. P.: The quasi-biennial oscillation: Analysis using ERA-40 data, J. Geophys. Res., 110, D08105, doi:10.1029/2004JD004941, 2005.

Perlwitz, J. and Harnik, N.: Observational Evidence of a Stratospheric Influence on the Troposphere by Planetary Wave Reflection, J. Climate, 16, 3011-3026, doi:10.1175/15200442(2003)016<3011:OEOASI > 2.0.CO;2, 2003.

Pfeffer, R. L.: A Study of Eddy-induced Fluctuations of the ZonalMean Wind Using Conventional and Transformed Eulerian Diagnostics, J. Atmos. Sci., 49, 1036-1050, doi:10.1175/15200469(1992)049<1036:ASOEIF>2.0.CO;2, 1992.

Pierrehumbert, R. T.: An essay on the parameterization of orographic gravity wave drag, in: Observation, theory and modelling of orographic effects, 1, 251-282, European Centre for Medium Range Weather Forecasts, 1986.

Randel, W. J., Udelhofen, P., Fleming, E., Geller, M., Gelman, M., Hamilton, K., D., K., Ortland, D., Pawson, S., Swinbank, R., Wu, F., Baldwin, M. P., Chanin, M. L., Keckhut, P., Labitzke, K., Remsberg, E., Simmons, A. J., and Wu, D.: The SPARC Intercomparison of Middle-Atmosphere Climatologies, J. Climate, 17, 986-1003, doi:10.1175/15200442(2004)017<0986:TSIOMC>2.0.CO;2, 2004.

Randel, W. J., Garcia, R., and Wu, F.: Dynamical Balances and 
Tropical Stratospheric Upwelling, J. Atmos. Sci., 65, 35843595, doi:10.1175/2008JAS2756.1, 2008.

Renwick, J. A.: Trends in the Southern Hemisphere polar vortex in NCEP and ECMWF reanalyses, Geophys. Res. Lett., 31, L07209, doi:10.1029/2003GL019302, 2004.

Richter, J. H., Sassi, F., Garcia, R. R., Matthes, K., and Fischer, C. A.: Dynamics of the middle atmosphere as simulated by the Whole Atmosphere Community Climate Model, version 3 (WACCM3), J. Geophys. Res., 113, D08101, doi:10.1029/2007JD009269, 2008.

Scaife, A. A., Butchart, N., Warner, C. D., and Swinbank, R.: Impact of a spectral gravity wave parameterization on the stratosphere in the met office unified model, J. Atmos. Sci., 59, 1473 $1489,2002$.

Schoeberl, M. R. and Strobel, D. F.: The Zonally Averaged Circulation of the Middle Atmosphere, J. Atmos. Sci., 35, 577-591, doi:10.1175/1520-0469(1978)035<0577:TZACOT > 2.0.CO;2, 1978.

Scinocca, J. F. and McFarlane, N. A.: The parametrization of drag induced by stratified flow over anisotropic orography, Quart. J. Roy. Meteor. Soc., 126, 2353-2393, 2000.

Screen, J. A. and Simmonds, I.: Erroneous Arctic Temperature Trends in the ERA-40 Reanalysis: A Closer Look, J. Climate, 24, 2620-2627, doi:10.1175/2010JCLI4054.1, 2011.

Seol, D. I. and Yamazaki, K.: Residual mean meridional circulation in the stratosphere and upper troposphere: Climatological aspects, J. Meteor. Soc. Japan, 77, 985-996, 1999.

Shepherd, T. G. and Shaw, T. A.: The Angular Momentum Constraint on Climate Sensitivity and Downward Influence in the Middle Atmosphere, J. Atmos. Sci., 61, 2899-2908, doi:10.1175/JAS-3295.1, 2004.

Smith, A. K. and Lyjak, L. V.: An Observational Estimate of Gravity-Wave Drag From the Momentum Balance in the Middle Atmosphere, J. Geophys. Res., 90, 2233-2241, 1985.
Song, Y. and Robinson, W. A.: Dynamical mechanisms for stratospheric influences on the troposphere, J. Atmos. Sci., 61, 1711-1725, doi:10.1175/15200469(2004)061<1711:DMFSIO>2.0.CO;2, 2004.

Thompson, D. W. J. and Solomon, S.: Interpretation of recent Southern Hemisphere climate change, Science, 296, 895-899, doi:10.1126/science.1069270, 2002.

Thompson, D. W. J. and Wallace, J. M.: Annular modes in the extratropical circulation. Part I: Month-to-month variability, J. Climate, 13, 1000-1016, doi:10.1175/15200442(2000)013<1000:AMITEC>2.0.CO;2, 2000.

Thorne, P. W.: Arctic tropospheric warming amplification?, Nature, 455, E1-E2, doi:10.1038/nature07256, 2008.

Uppala, S. M., Kallberg, P. W., Simmons, A. J., Andrae, U., Bechtold, V. D., Fiorino, M., Gibson, J. K., Haseler, J., Hernandez, A., Kelly, G. A., Li, X., Onogi, K., Saarinen, S., Sokka, N., Allan, R. P., Andersson, E., Arpe, K., Balmaseda, M. A., Beljaars, A. C. M., Van De Berg, L., Bidlot, J., Bormann, N., Caires, S., Chevallier, F., Dethof, A., Dragosavac, M., Fisher, M., Fuentes, M., Hagemann, S., Holm, E., Hoskins, B. J., Isaksen, L., Janssen, P. A. E. M., Jenne, R., McNally, A. P., Mahfouf, J. F., Morcrette, J. J., Rayner, N. A., Saunders, R. W., Simon, P., Sterl, A., Trenberth, K. E., Untch, A., Vasiljevic, D., Viterbo, P., and Woollen, J.: The ERA-40 re-analysis, Quart. J. Roy. Meteor. Soc., 131, 2961-3012, doi:10.1256/qj.04.176, 2005.

van Noije, T. P. C., Eskes, H. J., van Weele, M., and van Velthoven, P. F. J.: Implications of the enhanced Brewer-Dobson circulation in European Centre for Medium-Range Weather Forecasts reanalysis ERA-40 for the stratosphere-troposphere exchange of ozone in global chemistry transport models, J. Geophys. Res., 109, D19308, doi:10.1029/2004JD004586, 2004.

Weare, B. C.: Dynamical modes associated with the Antarctic ozone hole, Atmos. Chem. Phys., 9, 5403-5416, doi:10.5194/acp-9-5403-2009, 2009. 